\title{
'BETTER MAKE IT A DOUBLE': PERCEIVED RELATEDNESS INCREASES REPORTED ATTRACTIVENESS
}

\author{
A Thesis \\ presented to \\ the Faculty of California Polytechnic State University, \\ San Luis Obispo
}

\author{
In Partial Fulfillment \\ of the Requirements for the Degree \\ Master of Science in Psychology
}

by

Benjamin R. Ainley

March 2011 
(C) 2011

Benjamin R Ainley

ALL RIGHTS RESERVED 


\section{COMMITTEE MEMBERSHIP}

TITLE: 'Better Make it a Double': Perceived Relatedness Increases Reported Attractiveness

AUTHOR: Benjamin R. Ainley

DATE SUBMITTED: March $3^{\text {rd }}, 2011$

COMMITTEE CHAIR: Jason Williams, PhD.

COMMITTEE MEMBER: Kelly Moreno, PhD.

COMMITTEE MEMBER: Robin Lewis, PhD. 


\title{
ABSTRACT \\ 'BETTER MAKE IT A DOUBLE': PERCEIVED RELATEDNESS INCREASES
}

\section{REPORTED ATTRACTIVENESS}

\author{
Benjamin Ralph Ainley
}

Sexual selection shaped psychological mechanisms in both sexes to assess potential mates for evidence of mate quality (Buss, 2005). Attraction preferences are one such mechanism (Sugiyama, 2005) and physical attraction preferences are sensitive to fitness-promoting traits present in a potential mate. Physically attractive traits are thought to act as signals of good genetic quality (Neff \& Pitcher, 2005) and are preferred because of the advantage such quality bestows towards reproductive success. Specifically, genetic quality is proposed to be a biological requirement necessary for physically attractive traits to develop and be maintained (Johnstone \& Grafen, 1993). Furthermore, genetic quality is heritable to offspring, thereby increasing offspring reproductive success (Orr, 2009).

All mating decisions inherently involve trade-offs due to costs inflicted on time and resources when choosing a long-term mate. Assessing a mate for genetic quality is imperative to ensuring one selects a quality mate with heritable fitness benefits towards offspring reproductive success (Buss, 2005). In order to minimize costs and maximize benefits when making mate selection decisions, humans use multiple and redundant signals of mate quality (Fink \& Penton-Voak, 2002; Møller \& Pomiankowski, 1993). Accordingly, this study supposed that siblings act as redundant signals of genetic quality that would factor into mating decisions. Because genetic quality is heritable (Houle, 1991) and visible through physical attractiveness (Thornhill \& Gangestad, 1999), this study explored the possibility that knowledge of relatedness influenced attractiveness judgments of human faces.

Supporting the main hypothesis of the current study, siblings affected judgments of physical attractiveness for target faces. Analyses showed this effect to be driven entirely by female raters for both male $[\mathrm{t}(62)=3.87, \mathrm{p}<.001]$ and female $[\mathrm{t}(61)=2.24$, $\mathrm{p}=.029]$ target faces. Secondary analyses examining the effects of sibling pair attractiveness differences (low vs. high) showed that relatedness significantly increased female ratings of facial attractiveness for both low and high facially attractive male and low facially attractive female target faces. Results offer two possible conclusions as to the role relatedness may serve in mate quality assessments that align with parental investment as well as kin selection assumptions.

Keywords: Physical Attraction, Siblings, Sexual Selection, Mate Quality 


\section{ACKNOWLEDGMENTS}

This author would like to thank all who have donated their time and energy towards this project:

To Dr. Williams for his overall guidance of this study and for providing the initial aim of our experimental gamble. To Dr. Lewis and Dr. Moreno for their contributions to the editing and critical evaluation of this paper as well as their efforts towards my clinical development. To Becky Powell and Beth Guadagni for editing the formatting and grammar so as to ensure that, if nothing else, this paper looked and sounded attractive. To Ellie Krumpholz and Christine Warren for assisting with the implementation and data collection of this study. 


\section{TABLE OF CONTENTS}

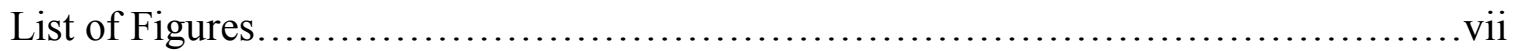

\section{Chapter}

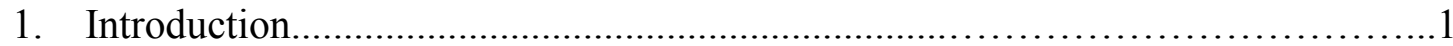

Problem and Purpose, 7

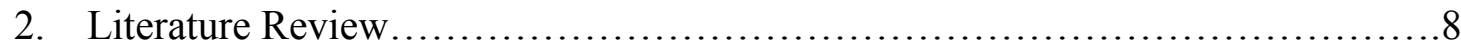

Attraction, 8

Physical Attraction, 10

Sexual Selection Models and Genetic Quality, 15

Attraction Trade-Offs, Signal Assessment, and Heritability, 23

Psychological Mechanisms for Signal Assessment, 25

Heritable Genes and Sibling Comparisons: The Current Study, 28

Summary and Hypothesis, 31

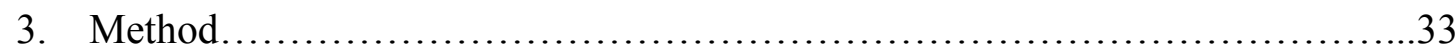

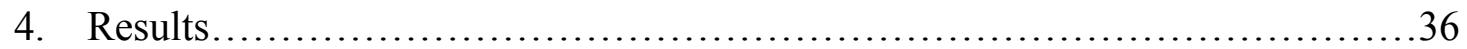

Pilot Group, 36

Female Raters, 36

Male Raters, 38

Effects of Sibling Differences in Attractiveness, 38

5. Discussion.

Limitations/Delimitations, 48

Future Directions, 51

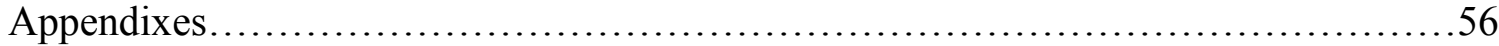

A. Rating Scale, 56

B. Pilot Rating Sheet, 57

Bibliography. 


\section{Figures}

Figures

Page

1. Means and standard errors of female participants' attractiveness ratings

for male faces and female faces in the related and baseline conditions.

2. Means and standard errors of male participants' attractiveness ratings

for female faces and male faces in the related and baseline conditions.

3. Means and standard errors of female participants' attractiveness ratings for the high attractiveness male faces and low attractiveness male faces in the related and baseline conditions.

4. Means and standard errors of female participants' attractiveness ratings for the high attractiveness female faces and low attractiveness female faces in the related and baseline conditions. 
The mouth, further, expresses only the thoughts of a man, while the face expresses a thought of nature: so that everyone is worth looking at, even if everyone is not worth talking to...yet the face does not lie: it is we who read what is not written there. (Schopenhauer, 1970/2004, p. 232-233)

\section{INTRODUCTION}

Natural selection is the process by which a species either demonstrate fitness, through specific adaptations, to survive the trials of life long enough to perpetuate itself or not (Darwin, 1871). In this sense, natural selection relates to viability and fitness is measured in terms of an organism's ability to survive in a particular environment and reproduce. However, Darwin also recognized that viability must not be the only measurement of fitness since some species seem to have adaptations that would endanger the possessor (e.g. the Peacock's conspicuous plumage; Darwin, 1871) and yet are common, even preferred, within their particular population.

In light of this issue, sexual selection was presented as an additional factor of natural selection (Darwin, 1871). Sexual selection implies that some adaptations, even though disadvantageous in terms of survival per se, will be selected for if they provide an advantage for reproductive success by making the carrier more desirable as a mate (Darwin, 1871; Buss, 2007). Using the peacock as an example, if the bright plumage of the peacock increases mating success (i.e. being selected as a mate and copulating), then any viability risk (e.g. increased predation) may be offset by an increase in reproductive success. Reproductive success denotes the production of offspring (Orr, 2009). Fitness is determined by one's ability to survive to sexual maturity, be selected as a mate, and achieve reproductive success (Orr, 2009).

Selection pressures, as understood by modern evolutionary theory, act on the genome of a species and it is the gene that relates to fitness (Dobzhansky, 1965; Neff \& 
Pitcher, 2005). Reproductive success is achieved by passing on one's genes to offspring, who then must achieve reproductive success of their own (Orr, 2009). Those genes that give the possessor an advantage in reproductive success will be passed on to future generations and are considered to be fitness-related (Fisher, 1915; Neff \& Pitcher, 2005;

Orr, 2009; Pierce, 2008). In turn, offspring inheriting fitness-related genes enjoy an advantage towards their reproductive success (Gangestad, Garver-Apgar, Simpson, \& Cousins, 2007; Shuster, 2009).

Genetic quality is defined as the contribution any gene makes towards fitnessrelated ends for an individual organism (Neff \& Pitcher, 2005). Differences in genetic quality exist because genes come in variations, known as alleles, and are inherited from both parents to compose the constellation of alleles that form the genotype of an individual (Pierce, 2008). A genotype is the collection of alleles an individual possesses inherited from both parents and forms the coding blueprint for all developmental processes. However, alleles are not sensible until they are expressed in the phenotype of an individual. The phenotype is the expressed trait of a characteristic that can be observed. Because phenotypes are dependent upon genes, they are potentially heritable to future offspring (Kosova, Abney, \& Ober, 2010; Møller \& Thornhill, 1997; Pierce, 2008; Rushton \& Bons, 2005).

Mate quality is the combination of multiple fitness traits possessed by a potential mate that make him or her desirable or undesirable as a mate. According to an evolutionary psychological framework, mate preferences relate directly to fitnessenhancing traits and preferences co-evolved with these traits (Lande, 1981). Universality of mate quality preferences are expected due to the consistent human problem of having 
to pass on genes through sexual transmission (Cosmides \& Tooby, 1989). Differential reproductive success resulted in an increased frequency of offspring that both preferred and possessed fitness-enhancing traits to such an extent that universality of mate preferences became a norm of sexual selection processes over time (Buss, 1995; Gangestad et al., 2007; Rowe \& Houle, 1996; Shuster, 2009).

Despite this universality, some variation in preference is expected since historically early environments (Buss, 1995; Duchaine, Cosmides, \& Tooby, 2001; Grammer, Fink, Møller, \& Thornhill, 2003) as well as relatively more recent ones (Gangestad, Haselton, \& Buss, 2006) had specific mate selection problems to resolve. The most prevalent differences are due to biological sex differences. Parental Investment Theory (Trivers, 1972) claims that biological differences between males and females in reproductive costs resulted in mate preferences that show some specificity for traits increasing reproductive success for each sex (Buss, 2003, 2007; Simpson \& Gangestad, 2001). Namely, males need only to contribute to the sexual act itself, but females must contribute substantially more time and energy towards offspring viability through pregnancy, birthing, and weening (Buss, 2007; Simpson \& Gangestad, 2001; Trivers, 1972).

According to Sexual Strategies Theory (Buss \& Schmitt, 1993), in order to maximize reproductive success different primary mating strategies for each sex minimize the costs associated with biological investment requirements. A short-term strategy entails seeking out a potential mate displaying signals of sexual availability and fertility whereas a long-term strategy entails reading cues of parental adeptness and investment willingness (Buss, 1989; Buss \& Schmitt, 1993), however both strategies require reading 
cues of sexual maturity in order to be certain a potential mate is fertile or able to provide resources (Buss, 2005; Jones et al., 1995; Muscarella \& Cunningham, 1996). Attraction preferences in a short-term strategy would focus on physical attraction since acquiring heritable genetic quality through copulation requires very little time or resource investment (Clarke \& Hatfield, 1989). Attraction preferences in a long-term strategy would focus on cues of status or resource availability as well as a willingness to invest in a mate and offspring (Buss, 1989).

Because of their lower investment requirement, it would be more advantageous for males to employ a short-term strategy in which preferences for physical markers of quality are most prevalent as well as a preference for sexual variety in order to copulate with as many females as possible (Buss \& Schmitt, 1993). Supporting this, males show a seemingly universal preference for physical attractiveness of both bodies and faces as the most weighted factor in mate quality judgments (Buss, 1988, 1989; Fisman, Iyengar, Kamenica, \& Simonson, 2006; Li, Balley, Kenrick, \& Linsenmeier, 2002; Schmitt \& Buss, 1996; Stroebe, Insko, Thompson, \& Layton, 1971). Men, more than women, show a preference for sexual variety (Schmitt et al., 2003) and Buss (2003), studying attraction behaviors, found that women emphasized displays of physical attractiveness as the most effective approach to attract males.

Females on the other hand would have a greater advantage employing a long-term mating strategy where preferences for cues of status and potential investment are desired (Buss \& Schmitt, 1993; Clarke \& Hatfield, 1989). As such, women show a weighted preference for traits associated with resource stability and a willingness to invest (Buss, 1989; Cunningham, Barbee, \& Pike, 1990; Dixson, Halliwell, East, Wignarajah, \& 
Anderson, 2003). However, evidence also shows that women's preference for physical traits indicating genetic quality (e.g. facial masculinity) significantly increase during the fertile phase of the menstrual cycle and employing a short-term strategy during this phase would be most advantageous in order to obtain good genes for offspring (Gangestad, Thornhill, \& Garver-Apgar, 2005; Johnston, Hagel, Franklin, Fink, \& Grammer, 2001). Thus, women, due to increased parental investment needs, must balance a trade-off between acquiring genetic quality through short-term mating tactics while also securing paternal investment from a long-term mate (Buss \& Schmitt, 1993; Penton-Voak, Jacobson, \& Trivers, 2004).

Men, however, must also balance mating trade-offs when engaging in mating behaviors because of female preference pressures (Buss, 2005; Buss \& Schmitt, 1993). Within human mating contexts, where serial monogamy is typical (Barber, 1995; Buss, 1995), mate preferences are exercised by both males and females, and both sexes compete along the parameters set by the opposite sex's preferences in a mate (Buss, 2005; Puts, 2010; Thornhill \& Gangestad, 1996). Therefore, the male tendency towards a short-term mating strategy, though optimal, is curbed by women's preference for traits associated with long-term mate quality and mating access may only be given to men who can best compete within these parameters (Buss \& Schmitt, 1993; Puts, 2010). The benefits of the typically long-term commitment of human mating are that men can secure mating access and women can secure paternal investment (Buss, 2005); though, both sexes would be more selective when searching for a long-term mate due to the costs inflicted for choosing a mate of poor mate quality, including poor genetic quality. 
Puts (2010) supported this in his review of human mating preferences. Consistent with parental investment and sexual strategy advantages, male choice shaped female development of physically attractive traits and female choice shaped male development of physically dominant traits, which are attractive due to their association with formidability and status benefits. Li et al. (2002) found that sex-specific mate preferences aligned with these conclusions. However, their study also found that kindness, a characteristic associated with investment and parenting (Buss, 2005), was a close second in importance for both sexes and Buss (1989) found a similar result for multiple cultures studied. Thus, sex-specific preferences act as minimums in order to secure mates according to parental investment needs, however both sexes want characteristics (e.g. kindness) that would relate to continuous investment benefits that would be key in longterm mate quality (Buss, 2005; Li et al., 2002).

Furthermore, cheating behaviors (Buss \& Schmitt, 1993; Tooke \& Camire, 1991) highlight the trade-offs associated with human long-term mating. These behaviors may be due to unsuccessful mate retention and mate swapping when long-term mate requirements remain unmet (Buss, 2005) and a long-term relationship becomes too costly to reproductive success to be worth maintaining (Greiling \& Buss, 2000; Todd, Penke, Fasolo, \& Lenton, 2007). To select a mate who cannot truly provide in terms of long-term mating necessities would be costly in terms of time and energy, and it would behoove each sex to gather evidence that a target mate indeed possesses mate qualities that are beneficial for reproductive success. Thus, both sexes have developed psychological mechanisms geared towards signal assessments in order to limit the costs associated with 
mate choice decisions and these mechanisms would still be active and influential for modern mating behaviors (Cosmides \& Tooby, 1989; Cosmides,Barrett, \& Tooby, 2010). Problem and Purpose

In light of this, it is possible that sibling physical attraction comparisons could affect judgments of mate quality, since such comparisons would bring additional information when assessing the genetic quality of a potential mate. To this author's knowledge, no such investigations have been conducted to explore this possibility. The purpose of this study was to conduct an initial investigation of the potential influences relatedness may have regarding judgments of mate quality. The method focused on facial attractiveness, one aspect of physical attractiveness, and compared differences in attraction judgments of sibling pairs between subjects who knew they were related and subjects who did not. 


\section{LITERATURE REVIEW}

In beginning this exploration, two questions require further elaboration: how does physical attraction relate to genetic quality and in what way would siblings potentially be relevant influences in judgments of mate quality? A review of the literature provided adequate conclusions to these questions and gave merit to the assumption that relatedness may indeed influences one's judgments of mate quality.

\section{$\underline{\text { Attraction }}$}

From an evolutionary standpoint, attraction is a general psychological mechanism that influenced multiple choices made daily by human ancestors, ranging from living locations to social interactions (Grammer et al., 2003; Sugiyama, 2005). Specific attraction preferences that proved advantageous towards survival and reproductive success within multiple environments slowly became universal in human populations through differential fitness advantages they provided (Cosmides \& Tooby, 1989; Escasa, Gray, \& Patton, 2010; Sugiyama, 2005). Thus, universal attraction preferences were forged in past environments as humans faced multiple adaptive challenges to be overcome and these preferences currently motivate human mating behaviors (Buss, 2005; Kahn, Hottes, \& Davis, 1971).

Sexual attraction is a category of attraction encompassing mate preferences such as status, resource acquisition, intelligence, physical attractiveness, and multiple other factors that influence one's judgment of overall mate quality (Buss, 2005; Gangestad et al., 2007). Shackelford, Schmitt, and Buss (2005) identify three general factors of mate quality that appear throughout the literature: kindness/warmth, social status/financial resources, and physical attractiveness/health (p. 448). Their study further showed that 
though these domains are consistent across cultures, the weight given between and within them on mate quality assessments shift due to specific environmental challenges.

Several studies have found similar results (Geary, 1998, as cited by Schmitt, Couden, \& Baker, 2001; Sugiyama, 2004, 2005) and Buss (2009) claims the different weighting those preferences may be the causes of cultural differences rather than actual differences in particular preferences. Gangestad et al. (2006), operating under the assumption that masculinity in males signals underlying health benefits, found that female preferences for masculine male traits increases in societies where parasite prevalence is high when compared to societies where parasite prevalence is low. In both societies physical attraction was a significant preference, but facial masculinity, a factor of physical attraction, was weighted differently when making physical attractiveness judgments.

Relating to this, Escasa et al. (2010) studied the female mate preferences of an isolated Amazonian society and found further support of sex-specific attraction preferences according to parental investment predictions. Females significantly preferred males who were higher in status and better able to acquire resources. However, they also found that though status tends to be associated with age, women rated men between the ages of 25 to 30 as the most physically attractive and in this carried more weight than indicators of status and resource acquisition. Though, in societies where status and resource acquisition is strongly dependent on physical prowess it may not be surprising to find a female preference for men in their physical prime as this may be more predictive of both fertility and resource stability. 


\section{$\underline{\text { Physical Attraction }}$}

Physical attractiveness is one aspect of sexual attraction and indicates genetic quality in terms of either biological robustness (Grammer \& Thornhill, 1994; Lie, Rhodes, \& Simmons, 2010) or because they simply increase the likelihood of being selected as a mate and producing offspring by catering to opposite sex preferences (Burt, 1995; Fisher, 1915; Lande, 1981). Nonetheless, a physically attractive appearance is a mate preference for both sexes and seems consistently so across cultures studied thus far (Buss, 1989; Cunningham, Roberts, Barbee, Druen, \& Wu, 1995; Escasa et al., 2010; Hadjistavropoulos \& Genest, 1994; Langlois et al., 2000; Lee, Lowenstein, Ariely, Hong, \& Young, 2008; Maner et al., 2003; Miller \& Todd, 1998; Stroebe et al., 1971; Swami \& Tovée, 2005).

Support for this is shown by physical attraction's powerful influence on human behavior (Kahn et al., 1971; Langlois et al., 2000; Todd et al., 2007), even in more contemporary online interactions (Fiore, Taylor, Mendelsohn, \& Hearst, 2008). Kleck and Rubenstein (1975) found that subjects remembered, liked, and thought about an interaction with an attractive person more than an unattractive one after several weeks. In line with this, physical attractiveness is especially potent as a source of information for impression formation of others (Hagiwara, 1975), with attractive people being perceived as possessing more positive attributes in both personality (Dion, Berscheid, \& Walster, 1972) and mate quality (Roberts, Buchanan, \& Evans, 2004). Also, physically attractive males and females have significantly higher rates of mating success over less attractive others (Rhodes, Simmons, \& Peters, 2005), which would be a key advantage in overall reproductive success. 
Physical attraction preferences begin early in human development (Dion, 1973; Langlois, Roggman, Casey, \& Ritter, 1987) and continue to act as a key initial cue of attraction in general (Cavior \& Dokecki, 1973). Langlois, Roggman, and Rieser-Danner (1990) found that infants as young as 12 months old showed a significant increase in positive behaviors towards adults rated as facially attractive and played longer with facially attractive dolls. Physical attraction's role in sexual attraction becomes influential from puberty onwards, which would be expected given the role physical attraction plays in signaling sexual maturity to potential mates (Saxton, Caryl, \& Roberts, 2006).

Specific factors of physical attractiveness also seem fairly consistent in agreement across multiple cultures (reviewed by Gangestad \& Scheyd, 2005; Jones et al., 1995; Rhodes, 2006; Streeter \& McBurney, 2003; Sugiyama, 2004; though see Swami \& Tovée, 2005). Factors that have been given the most attention are symmetry (sometimes discussed in terms of fluctuating asymmetry; Grammer \& Thornhill, 1994; Scheib, Gangestad, \& Thornhill, 2003), averageness (Grammer \& Thornhill, 1994; Rhodes, Sumich, \& Byatt, 1999), and sexual dimorphism (Johnston et al., 2001; Singh, 1993). Rhodes (2006) completed a meta-analysis of the physical attraction literature, specifically facial attractiveness, and found these three traits were strongly associated with facial attractiveness judgments for all cultures studied, though averageness may be the least potent of these traits (Perrett, May, \& Yoshikawa, 1994).

An additional trait that may be a factor in attraction judgments, especially facial attraction, is skin condition; though, this has mainly been studied in women (Samson, Fink, \& Matts, 2010). It is suspected this trait acts as a reliable indicator of age, which is important in terms of judging potential fertility and health. Supporting this, negative 
correlations between physical attractiveness and age are seen in multiple cultures when judging the physical attractiveness of women (Buss, 1989). Fink, Grammer, and Matts (2006) found that skin condition was predictive both of youth and attractiveness in women. This is also evidenced by the success of the cosmetics industry in marketing campaigns which focus on the benefits of reducing visibility of skin blemishes or signs of aging (Samson et al., 2010).

Symmetry and averageness in facial and body morphology are clearly key contributors to judgments of physical attractiveness and act as general indicators of genetic quality in both sexes (Grammer \& Thornhill, 1994). However, sexual dimorphism appears to act as both a general and sex-specific signal of genetic quality and influences sexual behaviors more than the other factors (Rhodes et al., 2005). For both sexes, the development of sexual dimorphic traits begins at puberty (Johnston et al. 2001; PentonVoak \& Chen, 2004) and signal sexual maturity (Lynch \& Zellner, 1999; Singh \& Young, 1995). Sexual maturity indicators are important in terms of determining fertility in potential mates, a prerequisite for reproductive success in both sexes. There is evidence of a relationship between fertility/health perceptions and lower masculinity in women (Singh, 1993; Singh \& Young, 1995). Fertility was positively correlated with symmetry in men (Waynforth, 1998), but there is evidence that symmetry and increased masculinity are related for men (Gangestad \& Thornhill, 2003; Little et al., 2008).

In male bodies, sex hormones develop increased muscularity (Lynch \& Zellner, 1999; Neave \& Shields, 2008), whereas in female bodies sex hormone circulation results in fat distribution to the breasts and hips (Singh, 1993; Singh \& Young, 1995). These sexspecific differences in body traits seem to be consistently related to physical attraction 
preferences for both sexes across multiple cultures (Barber, 1995; Cunningham et al., 1995; Dixson et al., 2003; Singh \& Young, 1995). Streeter and McBurney (2003) found that the waist-to-hip ratio discovered by Singh (1993) was indeed predictive of male sexual preferences in female bodies and this finding was consistent for multiple cultures (Dixson, Sagata, Linklater, \& Dixson, 2010). According to Singh (1993), though body mass index may vary between cultures, an optimal ratio between waist to hips of approximately .7 is most predictive of female attractiveness judgments and the images of the female "hourglass figure" near this ratio activates reward and decision processing centers in the brains of male viewers (Plateck \& Singh, 2010). Likewise, Frederick and Haselton (2007) showed evidence that women prefer a muscular male body type over less muscular or overweight typologies when making mate selections.

Despite the general attractiveness of sexual dimorphic body traits, sexual dimorphism in faces seems to be a source of sex-specific attraction differences. For female faces, genetic quality is related to fertility and fecundity in which age plays a significant role, which are signaled by neotenous facial features typical of low facial masculinity (Jones et al., 1995). Sex hormones produce full lips, large eyes, and narrow lower jaws and these constitute a feminine, youthful face (Cunningham et al., 1995). Feminine facial features are preferred by men significantly more than masculine or average variations (Cunningham et al., 1995; Johnston et al., 2001; Perrett et al., 1994; Puts, 2010; Rhodes, 2006).

Jones et al. (1995) argue that neotenous facial features in women are reliable indicators of age, which is predictive for both fertility and fecundity. Men prefer such features because of the advantages towards reproductive success provided by picking a 
mate who is able to produce offspring (i.e. fertility) and can do so for an extended period of time (i.e. fecundity). Jones et al. (1995) offers support for this conclusion by showing that females were perceived as more attractive to the extent that their predicted ages, calculated from facial measurements, were less than their actual ages and this result was significant for multiple cultural groups.

For male faces, genetic quality is related to sexual maturity and secondary gains associated with dominance, such as advantages in terms of status and resource acquisition (Gangestad \& Scheyd, 2005; Puts, 2010). Male sex hormones produce characteristics of masculinity (Penton-Voak \& Chen, 2004), such as large lower jaw, prominent cheekbones and brow ridges, thick eyebrows (Grammer \& Thornhill, 1994; Johnston et al., 2001). Masculine facial features are generally found to be attractive to women (Fink \& Penton-Voak, 2002; Scheib et al., 1999; Johnston et al., 2001), though this conclusion is debatable (Penton-Voak et al., 2004; Saxton, Little, Rowland, Gao, \& Roberts, 2009). Muscarella and Cunningham (1996) found that male facial hair, an aspect of masculinity, is attractive but only when slightly beyond a clean-shaven look. They conclude that facial hair acts as a signal of sexual maturity, but full beards may function as an intimidating factor to defend against rivals, which may also intimidate potential mates.

Indeed, the equivocal evidence seems attributable to masculinity's negative association to aggression (Carré, McCormick, \& Mondloch, 2009; Puts, 2010; Sell et al., 2009) and lower paternal investment (Little, Burt, Penton-Voak, \& Perrett, 2001). Neave, Laing, Fink, and Manning (2003) concluded in their study that facial masculinity may be more indicative of dominance and status rather than as a purely sexual ornament. Considering that women tend to seek out social status in a potential mate (Buss, 1989), 
this conclusion would still show facial masculinity as an attraction preference in that it signals sexual maturity as well as possesses further fitness advantages in terms of resource acquisition and status (Puts, 2010).

This is consistent with parental investment theory (Trivers, 1972). Women have higher parental investment requirements than men and require consistent resources from paternal investment to ensure offspring viability. This pressures women to then choose a less masculine male in order to negate possible costs of not being able to secure longterm investment from a masculine male, despite the advantage this would have in terms of status and resource availability (Buss, 2005). In line with this, female preference for masculine faces increases during the fertile phase of ovulation (Johnston et al., 2001; Jones et al., 2008). Gangestad et al. (2007) found that during the fertile phase of ovulation women show an increased interest in physical attractiveness as well as increasingly prefer muscularity and facial masculinity. Jones et al. (2008) examined multiple related studies on masculine facial preferences for women during the menstrual cycle and came to a similar conclusion. Furthermore, women of higher physical attractiveness prefer more masculine men regardless of fertility status and it is thought they do so because they would be able to secure long-term investment from masculine males through their own higher mate value (Little et al., 2001).

\section{$\underline{\text { Sexual Selection Models and Genetic Quality }}$}

From an evolutionary perspective, two models of sexual selection best describe the relationship between physical attractiveness and genetic quality: the "Good Genes" theory (a.k.a. Immunocompetence-Handicap hypothesis) and Fisher Runaway theory. Both theories hold that the development of physically attractive traits require genetic 
quality and this quality is in turn broadcasted to potential mates through the display of such traits. However each theory defines genetic quality differently.

The "Good Genes" theory of sexual selection supposes that sexually attractive traits are preferred because they signal underlying condition in terms of robust immune system competence and health (Grammer \& Thornhill, 1994). Sexually attractive traits and "good genes" are related through the concept of phenotypic condition. Phenotypic condition is the ability of an organism to efficiently allocate energy towards fitnessrelated ends (Thornhill \& Gangestad, 1999). Namely, physically attractive traits are condition-dependent for expression and are handicapped by limited energy allotment towards either physically attractive traits or viability (Folstad \& Karter, 1992; Grafen, 1990a, 1990b; Thornhill \& Gangestad, 1993). If, however, an individual has a genetically robust immune system, this handicap is more easily accommodated and the individual can expend more energy towards the development of sexually attractive traits (Mitton, 1993; Møller, 1997; Møller \& Pomiankowski, 1993; Shackelford \& Larsen, 1999).

It is thought that immunocompetence is partially made possible by heterozygosity. Heterozygosity refers to the inheritance of different alleles for a given location in the genotype (Hansson \& Westerberg, 2002). Heterozygotes, as opposed to homozygotes, have more gene variety and it is suspected this variety allows for increased immunocompetence and an increase in energy allocation efficiency towards fitness related ends (Mitton, 1993). Of particular interest is heterzygosity at the Major Histocompatibility Complex (MHC, sometimes referred to as Human Leukocyte Antigen, HLA) because MHC-related genes affect immune system functions (Lie et al., 2010). Heterozygosity here would be beneficial since it would provide a wider range of 
pathogen or parasite identification by the immune system, effectively increasing overall immune system resistance (Folstad \& Karter, 1992). Heterozygosity of MHC-related alleles would provide health benefits, both directly and indirectly, for potential mates and offspring (Roberts et al., 2005b) as well as avoid problems associated with inbreeding (Blouin \& Blouin, 1988; Garver-Apgar, Gangestad, Thornhill, Miller, and Olp, 2006).

However, evidence supporting a direct preference for heterozygosity in potential mates has been equivocal (Jacob, McClintock, Zelano, \& Ober, 2002; Jones et al., 2008; Lie, Rhodes, \& Simmons, 2008; Roberts \& Little, 2008; Roberts et al., 2005a; Thornhill et al., 2003). In support of heterozygosity as a mate preference, Lie et al. (2010) found that both males and females preferred faces of the opposite sex that associated most with HLA dissimilarity. Roberts et al. (2005b) found a similar result for women rating male faces only. MHC-dissimilar women also seem to have increased mating success and males may prefer MHC-dissimilarity across mating strategies (Lie et al., 2010). GarverApgar et al. (2006) found that in couples with MHC similarity, women reported lower sexual satisfaction and decreased sexual behavior as well as increased infidelity, increased fantasies about infidelity, and increased attraction towards men other than their partners. Also, Ober et al. (1985) found adverse effects on fertility due to HLA-similarity, including increased miscarriages.

Phenotypic condition, as signifying genetic quality through immune system and biological efficiency, allows for two biological attributes related to the attractiveness of physical traits. One attribute is developmental stability, which supposes that physical characteristics are vulnerable to environmental stressors that occur during development (Møller \& Pomiankowski, 1993; Parsons, 1990). These stressors force an organism to 
allocate energy and resources towards viability rather than towards maintaining or developing symmetrical and average physical characteristics and cause deviations in these traits. These deviations affect an individual's physical attractiveness, therefore physical attractive traits are thought to be possible because good genetic quality allows for efficient energy distribution towards maintaining both viability and symmetrical physical traits (Scheib et al., 1999; Grammer \& Thornhill, 1994).

A second contributing physical attribute is sexual dimorphism. Sex hormones cause sex-typical physical changes for males and females beginning at puberty and increased circulating levels of these hormones are necessary for sexual dimorphic characteristics to be developed and maintained (Johnston et al., 2001; Penton-Voak \& Chen, 2004). However, sex hormones can act as immunosuppressants, which limits how much can be circulating without significantly affecting the viability of an organism (Fink \& Penton-Voak, 2002; Thornhill \& Gangestad, 1993). As is the case for developmental stability, individuals possessing good immunocompetence can afford to develop more extreme sexually dimorphic traits because he or she can handle increased hormone circulation without significantly jeopardizing his or her survival (Grafen, 1990a).

Despite this, a potential limitation to the "Good Genes" model is the inconclusive evidence supporting the connection between sexually attractive traits and actual health benefits (Rhodes, 2006; Rhodes et al., 2001; Rhodes, Chan, Zebrowitz, \& Simmons, 2003; Roberts et al., 2004). Fertility, an aspect of reproductive health, was significantly correlated with the physically attractive trait of symmetry, though this finding was limited to men (Waynforth, 1998). Some positive correlations between physically attractive traits and actual health benefits have been found (Henderson \& Anglin, 2003; 
Shackelford \& Larsen, 1999; Thornhill \& Gangestad, 2006), though many of these correlations were weak (Rhodes et al., 2003). Sefcek, Brumbach, Vasquez, \& Miller (2006) found that Good Genes may relate to health for males, but not for females, and it may be that different selection processes have acted on specific traits for each sex rather than one process for all traits in both sexes, with some traits being due to immunocompetence and some due to alternative processes (e.g. Fisher Runaway). As Rhodes (2006) concluded, though there may be limited evidence to support physical attractiveness' connection to health benefits, health has typically been poorly measured and many studies show limited sampling sizes, so conclusions about limitations of the "Good Genes" theory may be premature.

One explanation for the mixed findings regarding the connection between Good Genes and health is the "Bad Genes" hypothesis. Zebrowitz and Rhodes (2004) suggest that mate preferences may be more wired for assessing the presence of "bad genes" rather than good genes. Their study found that judgments of lower health and intelligence were more accurate when correlated with a lower expression of physically attractive traits. Considering the extreme costs to reproductive success that poor mate selection would inflict, being more accurate in detecting mates with poor genetic quality in order to avoid selecting him or her as a mate would outweigh the benefits of being sensitive to very good genes present in a high quality mate (Buss, 2003; Buss \& Schmitt, 1993; Getty, 2002; Grammer et al., 2003; Grammer, Fink, Møller, \& Manning, 2005; Zebrowitz \& Rhodes, 2004). In this sense, the ability to produce and maintain physically attractive traits may be indeed rely on genetic quality in terms of energy allotment efficiency (i.e. good condition; Grammer et al., 2005), but this may not necessarily ensure major health 
benefits rather than a more efficient ability to produce physically attractive traits, which provide advantages towards reproductive success in and of itself (Getty, 2002). This concept relates more to Fisherian processes and will be reviewed below.

Overall, it is thought that if physically attractive traits in bodies and faces are related to genetic quality, then there must be interaction between them due to their dependence on good condition for development. Supporting this, Little et al. (2008) found a link between symmetry and sexual dimorphism for both sexes across cultures and species (macaques). Gangestad and Thornhill (2003) found a similar correlation between masculinity and symmetry in faces and bodies of male subjects and a meta-analysis conducted by Møller and Thornhill (1998) showed similar results. For women, the same correlation was found when low facial masculinity was present, which is expected due to biological sex differences in sexual dimorphism (Gangestad \& Thornhill, 2003). Saxton et al. (2006) showed that males with attractive faces also had attractive voices and consistency in judgments of attractiveness did not significantly arise until puberty.

Contrary to the "Good Genes" model, Fisher Runaway supposes that physically preferred traits relate to fitness because they increase the probability of an individual being preferred as a mate with no underlying health or fertility benefits (Fisher, 1915). Furthermore, sexually attractive traits can be present even at the expense of viability since opposite sex preferences for mates displaying such traits act as the limitation of their frequency in a species, not biological handicapping (Kalick, Zebrowitz, Langlois, \& Johnson, 1998; Lande, 1981). That is, it's not that an individual physiologically cannot produce a physically attractive trait more so than the trait produced is not preferred by mates and is therefore unattractive. 
Equilibrium is reached through counter-selection, rather than "handicapping," in which natural selection begins to factor back into sexual selection preferences as viability once again outweighs the extreme expression of sexually attractive traits (Fisher, 1915; Lande, 1981). In other words, it is not that an organism cannot physically produce more extreme physically attractive traits, as is the case for the "Good Genes" model. Rather, mate preferences for specific traits balance the advantages of possessing them regardless of viability costs or the costs are so extreme that the possessor no longer survives long enough or can compete successfully enough to achieve reproductive success (Fisher, 1915; Getty, 2002; Puts, 2010).

For Fisher Runaway sexual selection, as with "Good Genes" theory, fitness relates to an organism's ability to effectively acquire a mate and reproduce (Burt, 1995; Getty, 2002; Little, Jones, Penton-Voak, Burt, \& Perrett, 2002). However, genetic quality in Fisherian processes means that an organism has genes that produce sexually attractive traits and these traits provide fitness advantageous simply because they are preferred by potential mates rather than because they indicate viability advantages for the individual or for potential offspring (Kalick et al., 1998; Lande, 1981). As Burt (1995) states, "the benefits of choosing well are likely to be modest compared to the benefits of being chosen often" (p. 6).

Using health as an example of fitness advantages in Fisher Runaway selection, there is substantial evidence that sexually attractive traits merely increase perceived health (Gangestad et al., 2006; Rhodes et al., 2001). Jones et al. (2001) found a significant positive correlation between facially attractive traits and judgments of good health, however the authors state that this may be little more than a halo effect if evidence 
linking these traits to actual health remains unsubstantial. Getty (2002) suggested that Good Genes allow an organism to more efficiently convert energy into fitness gains despite any cost, including lower immune function (p. 367), and this would result in the production of physically preferred traits without significant health benefits. Though this calls into question the health advantages supposed by the Immunocompetence hypothesis (Rhodes et al., 2003; Roberts et al., 2004), the increased perception of health provided by physically attractive traits would still be advantageous in mate selection processes if it results in a preference advantage in mate selection processes (Fisher, 1915).

One theory that may explain the origins of mate preferences under Fisher Runaway is the Sensory Bias model. Sensory Bias claims that the connection between preferred traits and judgments of mate quality results from cognitive overlap (Elliot \& Niesta, 2008). That is, preferences from one domain of attraction simply overlapped with other attraction domains to produce preferences that have no real underlying significance (Elliot \& Niesta, 2008; Gangestad \& Scheyd, 2005). For example, the color red enhances physical attractiveness ratings and may do so simply because of a possible association to ripe fruit from earlier evolutionary history which may overlap into impressions of health despite no actual correlation (Elliot \& Niesta, 2008). The preference for ripe fruit became universal through differential survival for those who had better nutrition and by virtue of this overlap red became a universal influence on mate preferences as well though it holds no real underlying value for mate quality.

Overall, it may be that both the "Good Genes" and Fisher Runaway models are involved in sexual selection and need not be viewed as mutually exclusive. Shuster (2009) suggested some models simply appear as variations of the other and an integrative 
approach may be necessary to more accurately account for the complexity of human mating preferences and behaviors (Simpson \& Gangestad, 2001; Van Doorn \& Weissing, 2004). Supporting this, Kokko, Brooks, Jennions, and Morley (2003) showed how Sensory Bias and Fisher Runaway could be related or that "Good Genes" models could be an earlier stage of Runaway processes (Fisher, 1915; Møller \& Powmiankowski, 1993). Cornwell and Perrett (2008) encourage a multiple models approach to sexual selection and the authors state that the two may be too difficult to distinguish between to consider completely separate processes.

Attraction Trade-Offs, Signal Assessment, and Heritability

Simply desiring a high quality mate does not ensure reproductive success due to limitations that arise due to one's own mate value (Kalick \& Hamilton, 1986; Lee et al., 2008; Little et al., 2002; Murstein, 1972; Schackelford et al., 2005; Todd et al., 2007) and this presents trade-offs one must navigate if one is achieve reproductive success. For example, one's mate value often determines the quality level of a potential mate that one is able to secure (Penke, Todd, Lenton, \& Fasolo, 2007; Todd et al., 2007) and those higher in mate value are able to potentially secure mates of higher quality (e.g. good genetic quality as well as a good parent; Buss, 2005; Little et al., 2001). Often cited as evidence is the significant similarity in attitudes (Buss, 1984; Fiore \& Donath, 2005; Insko et al., 1973) and physical attractiveness (Buss, 1984; Kalick \& Hamilton, 1986; Lee et al., 2008; Murstein, 1972; Todd et al., 2007) human couples tend to share. This is thought to be due to a balancing effect between mate value and mate preferences where one may prefer a high quality mate but eventually, through trial and error, secures a mate more similar in quality to one's self (Kalick \& Hamilton, 1986; Todd et al., 2007). 
Because of the human tendency towards long-term mating, tradeoffs between signals of genetic benefits ("good genes") and direct benefits (e.g. paternal investment, protection/formidability, kindness; Buss \& Schmitt, 1993; Frederick \& Haselton, 2007) are the most apparent. A tradeoff both sexes face when seeking a long-term mate is between selecting a mate with genetic benefits or direct benefits (Frederick \& Haselton, 2007; Puts, 2010). Genetic benefits entail heritable attractive traits (e.g. physical attractive facial features) whereas direct benefits denote more immediate benefits (e.g. paternal investment; Frederick \& Haselton, 2007). Though it is possible to acquire a high quality mate in both areas, one's own mate value may result in an inability to secure long-term investment or an inability to acquire genetic benefits (Buss, 2005; Puts, 2010).

The reality of these tradeoffs in mate selection processes makes the honesty of physically attractive traits beneficial when assessing mate quality. Whether genetic quality equals immune system competence (Johnstone, 1995; Rowe \& Houle, 1996; Zahavi, 1977) or simply the ability to produce physically attractive traits (Fisher, 1915), it is apparent through physical attractiveness judgments and is difficult to fake, as evidenced by the necessity of modern plastic surgery procedures to manipulate the presence of physically attractive traits (Singh \& Randall, 2007). The logic is that one may be able to give off the perception that one is, for example, higher in status through the use of expensive clothes, grooming, etc (Haselton et al., 2005). However, one runs into difficulty in faking symmetry of facial features since it is dependent on genes for expression (Johnstone \& Grafen, 1993; Møller, 1997). Unless, of course, one can invest in surgical alterations to endow one with the appearance of physical attractiveness; even then, it could be said that physical traits are so difficult to fake that one must resort to 
such advanced methods and gives credit to the potency of physical attractiveness influences on human behaviors, sexual or otherwise.

In short, physical traits may be the most salient factors when making judgments of mate quality (Bereczkei \& Csanaky, 1996; Buss, 2007; Maner et al., 2003; Gangestad et al., 2007). By observing these, one can be more certain one is getting what one "pays" for since deception strategies, which are not uncommon in mate selection processes (Buss \& Schmitt, 1993; Tooke \& Camire, 1991; Haselton, Buss, Oubaid, \& Angleitner, 2005), are much more limited when attempted towards faking genetic quality signals apparent in physical morphology (Johnstone \& Grafen, 1993; Morris \& Morris, 2004). This honesty of physical signals would produce psychological mechanisms specifically wired to assess and desire the presence of such traits in a potential mate since it increases one's certainty one is selecting a quality mate (Buss, 2005).

\section{$\underline{\text { Psychological Mechanisms for Signal Assessment }}$}

Only those psychological mechanisms that proved more useful in resolving adaptive problems related to human mating and achieving reproductive success remain today (Buss, 1995, 2005; Gangestad et al., 2007). Assessing mate quality via physical traits are one such mechanism and help to maximize one's ability to select a quality mate while avoiding costs associated with choosing poor quality mates (Zebrowitz \& Rhodes, 2004). Furthermore, the more reliable information one can obtain the more likely one will be able to make good mating decisions when choosing a potential mate (Wells, Dunn, Sergeant, \& Davies, 2009).

According to the Multiple-Signal hypothesis (Møller \& Pomiankowski, 1993), humans allocate resources towards multiple signals of various aspects of mate quality to 
suit different fitness needs over the lifespan. Allocating resources towards multiple signals of independent aspects of mate quality would be more efficient in terms of advertising mate quality in order for potential mates to determine multiple factors related to cost and benefit trade-offs, thereby allowing a more accurate assessment of overall mate quality (Van Doorn \& Weissing, 2004). Multiple signals are also beneficial for physical traits since biological signals, though fairly honest, cannot be completely honest for a single given characteristic (Johnstone, 1995; Johnstone \& Grafen, 1993), due to a limitation of resource allotments to the maintenance of multiple traits, and it would be beneficial to observe multiple traits in order to gain an accurate picture of genetic quality.

Peters, Rhodes, and Simmons (2007) found support for the Multiple-Signal hypothesis by showing that faces and bodies act independently in overall physical attractiveness judgments. They suggest the body may be more reliable in terms of assessing lifestyle choices and status whereas the face may be more indicative of heritable aspects of quality. Similarly, Havlicek, Roberts, and Flegr (2005) found that women preferred the odor of psychologically dominant males during the fertile phase of the menstrual cycle, but not in non-fertile phases. This suggests that body odor acts as a separate signal of mate quality in addition to physical signals and provides contributing evidence towards judgments of mate quality.

The Redundant-Signal hypothesis proposes that overall condition is judged by observing the repetition of several condition-dependent sexual traits rather than by any single trait itself (Fink \& Penton-Voak, 2002). Redundant signals would be useful in order to ensure that the message of genetic quality are received by potential mates (Thornhill \& Grammer, 1999) and redundancy has been shown to be beneficial in 
organizing social (Pryor, Kott, \& Bovee, 1984) and genetic information (Morris \& Morris, 2004). Physical traits, such as symmetry, averageness, and sexual dimorphism, are thought to be redundant signals of genetic quality through trait optimization, which is what constitutes judgments of physical attractiveness. In support of this, Thornhill and Grammer (1999) found that faces and bodies may act in conjunction with each other in attraction ratings to ensure that genetic quality is signaled by both facially attractive traits and bodily attractive traits. In their review of multiple studies, Grammer et al. (2005) showed interactions between multiple physically attractive traits and aspects of genetic quality (e.g. health benefits).

However, resources, defined broadly as time and energy, are limited per organism (Houle, 1991) and physical traits would therefore be competing against each other for the resources necessary to be maintained (Van Doorn \& Weissing, 2004). Though Van Doorn and Weissing (2004) suggest that redundant displays may not be cost-effective in terms of individual resource allocation and may be deceiving in terms of judging overall condition, this conclusion may be unfounded. Good condition, as previously defined, is an organism's ability to efficiently allocate resources towards fitness-related ends (Mitton, 1993; Thornhill \& Gangestad, 1999). Therefore, good genetic quality would be signaled through physical attractiveness judgments precisely because the optimal development of contributing physical traits is dependent on good condition (Grafen, 1990a; Zahavi, 1977).

The importance of these models is their encapsulation of the complexity involved in mate preferences and the necessity to factor in multiple signals in order to reduce costs inherent in mating trade-offs. Assessing for multiple signals would be more advantageous 
in terms of gathering diverse, but related, information for formulating judgments of overall mate quality across time and contexts (Cosmides et al., 2010; Wells et al., 2009). As one of these multiple signals, physical attractiveness is itself composed of redundant signals of genetic quality (Thornhill \& Grammer, 1999) and is therefore an important factor in mating decisions if an individual is to select a mate with heritable benefits towards offspring reproductive success (Buss, 2005).

\section{Heritable Genes and Sibling Comparisons: The Current Study}

All models of sexual selection under modern evolutionary theory acknowledge that selection pressures ultimately act on the genome of a species and it is the gene that relates to fitness (Dobzhansky, 1965; Neff \& Pitcher, 2005). According to Mendelian Segregation, each individual inherits two alleles of each gene, one from each parent, and dominant genes become expressed in the phenotype whereas recessive genes remain silent (Pierce, 2008). As an example, an individual may have alleles for blue and brown eye pigment (genotype), but the individual visibly has brown eyes (phenotype), given that alleles for brown eyes are dominant over alleles for blue eyes when both are present in a genotype.

Because of alleles, fitness differences in genetic quality are possible, with those possessing alleles that produce sexually attractive traits being more likely to enjoy increased reproductive success (Pierce, 2008; Wright, 1931). Specific alleles are thought to be fitness-related if they produce traits that either increase viability or sexual attraction or both of those that possess them (i.e. reproductive success; Fisher, 1915; Neff \& Pitcher, 2005; Pierce, 2008). Thus, those that possess preferred physical traits are thought to possess the alleles necessary for their development and these genes are heritable, 
which benefits offspring reproductive success (Fisher, 1915; Neff \& Pitcher, 2005; Thornhill \& Gangestad, 1999; Pierce, 2008).

However, Mendelian Segregation and allele dominance potentially mask genetic quality that would be available to offspring because of phenotype differences in a potential mate. For this reason, fitness traits rely on multiple genes (Houle, 1991) and differences in phenotypes between siblings may be more indicative of minor genetic variance due to dominance rather than major differences in genetic quality (Clarke, 1998). One may assume, therefore, that sibling comparisons could offer an insight into potential genomic quality by way of integrating comparative signals of genetic quality exhibited by these related individuals.

For example, suppose a man has brown eyes and women prefer blue eyes. He would be rated lower in physical attractiveness despite the fact that he may actually have an allele for brown eyes and an allele for blue eyes but allele dominance hides the expression of blue eyes. Yet, his allele for blue eyes is potentially heritable to his offspring and would thereby increase offspring reproductive success if it becomes expressed in their phenotypes. Suppose further that this man has two brothers, both of whom have blue eyes. They would be rated higher in physical attractiveness because they possess eye color that is preferred by women. For this reason, it may be reasonable to suppose that the brown eyed man would be rated as more attractive if it is known he is brothers with the highly attractive men because women may consider there is underlying genetic quality that is not readily observable but may be conferred to offspring.

In line with this logic, the current study circumvents the arguments presented by sexual selection models as to the definition of genetic quality because both "Good 
Genes" and Runaway models depend on the heritability of attractive traits in order for either model to be evolutionarily relevant (Cornwell \& Perrett, 2008; Simpson \& Gangestad, 2001). Heritability of attractive traits is paramount to reproductive success because in any case the possessor of preferred traits would have an advantage in mating success over those who do not possess such traits or possess weaker versions (Cornwell \& Perrett, 2008; Kosova et al., 2010; Tesser, 1993; Wright, 1931). Furthermore, heritability determines that offspring can potentially inherit fitness-enhancing traits and enjoy advantages in reproductive success (Pierce, 2008).

Support for the heritability of physically attractive traits has been fairly consistent (Cornwell \& Perrett, 2008; Kosova et al., 2010; Grammer \& Thornhill, 1994; Rowe \& Houle, 1996; Rushton \& Bons, 2005). Miller and Todd (1998) offer an excellent summary of the mounting evidence that physically attractive traits relate to heritable genetic quality as well as review the evidence that humans have complex cognitive mechanisms shaped through selection processes to assess mate quality in order to influence the acquisition of quality genes for offspring. This stated, there would be significant advantages of comparing phenotypic quality (i.e. physical attractiveness) of heritable fitness-related traits between those of a similar genotypes (Houle, 1991; Lie et al., 2010; Miller \& Todd, 1998; Thornhill \& Gangestad, 1999) and it may be that humans use such comparisons in mating decisions.

\section{Summary and Hypothesis}

The relationship between physically attractive traits, genetic quality, and fitness hinges on heredity (Cornwell \& Perrett, 2008; Kosova et al., 2010). However, alleles differ from each other not only in terms of phenotype but also in expression probability 
due to dominance and Mendelian inheritance laws. An allele may either be dominant, expressed in the phenotype, or recessive, silent in the phenotype (Pierce, 2008) and allele distribution from parents to children follows laws Mendelian Segregation in which only half of alleles from each parent is randomly passed to offspring (Fisher, 1918; Pierce, 2008). Siblings share approximately $50 \%$ of their genes with each other and variations between siblings may be attributable to allele dominance (Fisher, 1918). Thus, there will be variations between siblings in condition and the development of condition-dependent fitness-related physical traits. However, if one observes the physical attractiveness of siblings, which hinges on genetic quality/condition for expression, it is possible one would obtain a better assessment of heritable genetic quality and this would in turn influence judgments of physical attractiveness of a target mate.

This study supposes physical attractiveness is the compilation of redundant signals of genetic quality and good condition. Because genetic quality is heritable, sibling physical attractiveness may influence judgments of the physical attractiveness of a target sibling since more information relating to genetic quality becomes available via comparisons between related individuals. As a factor of mate quality judgments, physical attractiveness, specifically facial attractiveness, would be one salient source of information related to genetic quality (Lie et al., 2010; Peters et al., 2007; Salter, 1996) and may be an appropriate starting point from which to explore potential influences sibling comparisons may have on judgments of attraction and mate quality.

The main hypothesis is that knowledge of sibling relatedness will significantly affect judgments of physical attraction of target faces. Because genetic quality is being evaluated, the effect of relatedness should be such that siblings of higher attractiveness 
are negatively affected by their lesser attractive sibling whilst siblings of lower attractiveness will be positively affected by their more attractive sibling. In this way, what is essentially occurring is an overall movement towards a genomic average for individuals with related genes. 


\section{METHOD}

\section{Primary Experiment}

\section{$\underline{\text { Participants }}$}

The sample (64 female, 56 male) was composed of undergraduate introductory psychology students who either participated as a partial requirement for course credit or who were compensated with minor extra credit points. Anonymity of student volunteers was insured by not collecting names of participants other than personal information such as age, sex, major, and ethnic identification. Experimental methods were within ethical standards as approved by the university Human Subjects Committee. Informed Consent was verbally stated and provided in writing before each experimental session to inform each subject of his or her rights. Participants were fully debriefed following the experiment.

\section{$\underline{\text { Design }}$}

The primary experiment employed a between-subjects independent groups design. Participants were randomly assigned to conditions and either rated the attractiveness of faces presented sequentially in random order (baseline condition) versus presented sequentially explicitly as siblings (related condition).

\section{$\underline{\text { Instruments and Procedure }}$}

The stimuli were faces presented in PowerPoint slideshows. Photos of sibling pairs were obtained from online sources and selected on the basis that 1) they contained same-sex sibling pairs and 2) they were employing posed smiles. Research suggested the use of actual faces rather than composites or altered photos since this increases ecological validity of ratings (Mealy, Bredgestock, \& Townsend, 1999). All procured photos 
included both same-sex siblings; 20 photos, 10 brother pairs and 10 sister pairs, resulted in a total of 40 individual target faces.

These photos were cropped to include just the faces and to create individual photos of each sibling face. Though it has been found that attraction ratings tend to be consistent across cultures (Rhodes, 2006), we employed photos consisting solely of Caucasian faces in order to control for cultural generalizations and control for possible novelty effects due to racial differences. All data were collected in classrooms with stimuli projected onto centrally located, standard sized projection screens.

In the baseline condition, these individual photos were presented in random order for six seconds a piece, to avoid participant inferences of sibling relatedness. In the related condition, participants were informed they were rating pairs of siblings. These stimuli were sequentially presented one right after the other, and with textual reminders (e.g. "Rate this individual," "Rate his brother"). In both conditions, presentation order of photos were reversed counter-balanced to control for order effects. Because there is evidence that people seen together will produce a single assimilation rating (i.e. a halo effect; Geiselman, Haight, \& Kimata, 1984; Wedell, Parducci, \& Geiselman, 1987), care was taken to show each target face by itself and sequentially.

The rating sheet was composed of letters corresponding to the individual target faces and a six-point Likert scale was used for participants to circle their judgment of attractiveness for each face. The scale, adopted from Dixson et al. (2010), contained the following options: 0-“unattractive," 1-“only slightly attractive," 2-“mildly attractive," 3"moderately attractive," 4-“very attractive," and 5-“extremely attractive." The scale also 
contained a section for subjects to identify their academic major, age, sex, and ethnic identity (Appendix A). 


\section{RESULTS}

\section{$\underline{\text { Pilot Group }}$}

Since this study was interested in examining the effect of higher attractiveness siblings on lower attractiveness siblings and vise verse, a pilot study of 25 females $\left(\mathrm{M}_{\mathrm{age}}=22.24\right.$ years $)$ and six males $\left(\mathrm{M}_{\mathrm{age}}=22.17\right.$ years $)$ were given a force choice of attractiveness between simultaneous siblings (Appendix B). This allowed us to determine the more and less attractive sibling without order effects. The 10 pairs of female faces were followed by the 10 pairs of male faces and preferences were tallied. If one sibling achieved more than a two-thirds preference that person was deemed the higher and the other the lower. The more ambiguous cases were not included in the subsequent pair-wise analysis discussed below. Seven of the ten female pairs showed clear preferences, as did eight of the ten male pairs.

\section{$\underline{\text { Female Raters }}$}

Because the current study was primarily interested in mate selection, and therefore were most interested in cross-gender ratings, we first examined females rating male faces. Overall an independent sample t-test showed statistical significance $[\mathrm{t}(62)=3.87, \mathrm{p}<.001]$. When rating male faces, being presented as a sibling $(\mathrm{M}=2.23$, $s d=.45$ ) increased ratings significantly higher than being presented without siblings $\left(\mathrm{M}=1.71, \mathrm{sd}=.58, \mathrm{~d}^{\prime}=1.0\right)$. Interestingly, an independent sample t-test also revealed significant differences for females rating female faces $[\mathrm{t}(61)=2.24, \mathrm{p}=.029]$. When rating female faces, being presented as a sibling $(\mathrm{M}=2.66, \mathrm{sd}=.43)$ increased attractiveness ratings significantly higher than being presented without siblings $(M=2.36, \mathrm{sd}=.58$, $\mathrm{d}^{\prime}=.58$; Figure 1). 


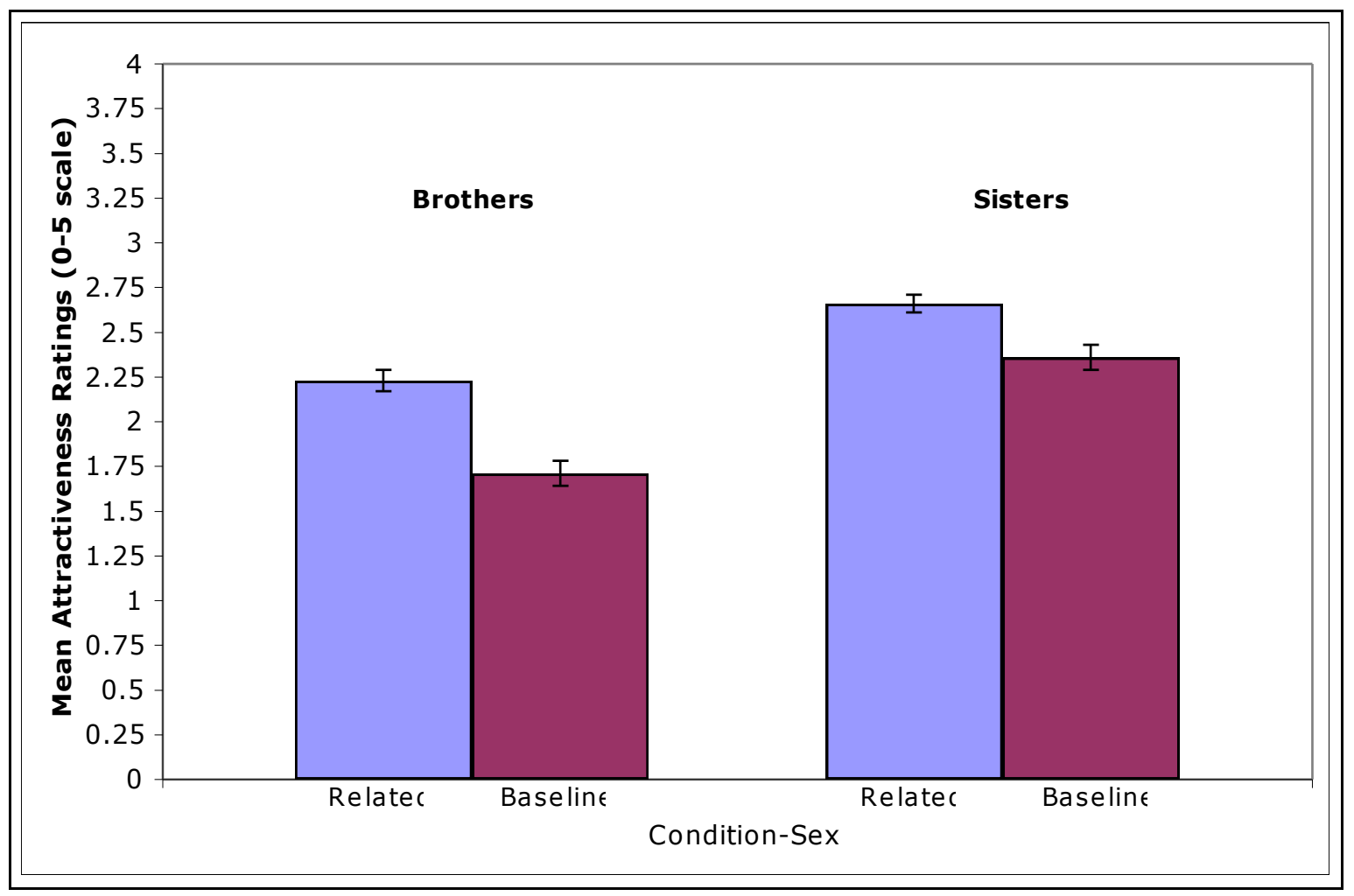

Figure 1. Means and standard errors of female participants' attractiveness ratings for male faces and female faces in the related and baseline conditions. 


\section{$\underline{\text { Male Raters }}$}

Unlike the female participant findings, male participants rating female faces showed no significant differences between the related $(\mathrm{M}=2.56, \mathrm{sd}=.49)$ and baseline $\left(\mathrm{M}=2.54, \mathrm{sd}=.35, \mathrm{~d}^{\prime}=.05\right)$ conditions $[\mathrm{t}(56)=.17, \mathrm{p}=.87]$. Males rating male faces was examined and overall an independent sample t-test showed no statistical significance $[\mathrm{t}(55)=.69, \mathrm{p}=.49]$ between related $(\mathrm{M}=2.04, \mathrm{sd}=.60)$ and baseline $(\mathrm{M}=1.91, \mathrm{sd}=.70$, $\mathrm{d}^{\prime}=.2$ ) conditions (Figure 2).

\section{$\underline{\text { Effects of Sibling Differences in Attractiveness }}$}

We hypothesized that the higher rated siblings would be rated lower when presented with their lower rated sibling, and vise verse, and we therefore analyzed separately the higher and lower rated siblings to see if ratings move toward an average. The determination of the high and low siblings was discussed in the pilot study above; however, in all cases the ranking of the higher sibling from the pilot study corresponded to a higher rating in the baseline attractiveness condition, which provided strong support for the rater reliability of attractiveness for each target face. Therefore, four composite variables were computed for each participant: the average for the higher rated female sibling (female high), the lower rated female sibling (female low), the higher rated male sibling (male high), the lower rated male sibling (male low), and these were compared between related and baseline conditions using an independent samples t-test.

Given the significant effects for female participants rating female and male siblings, both high and low rated siblings were analyzed for these separate conditions. For both high and low rated males, significant attractiveness increases were found when they were presented as siblings. For the male highs $[\mathrm{t}(62)=4.8, \mathrm{p}=.008]$ the mean of the 


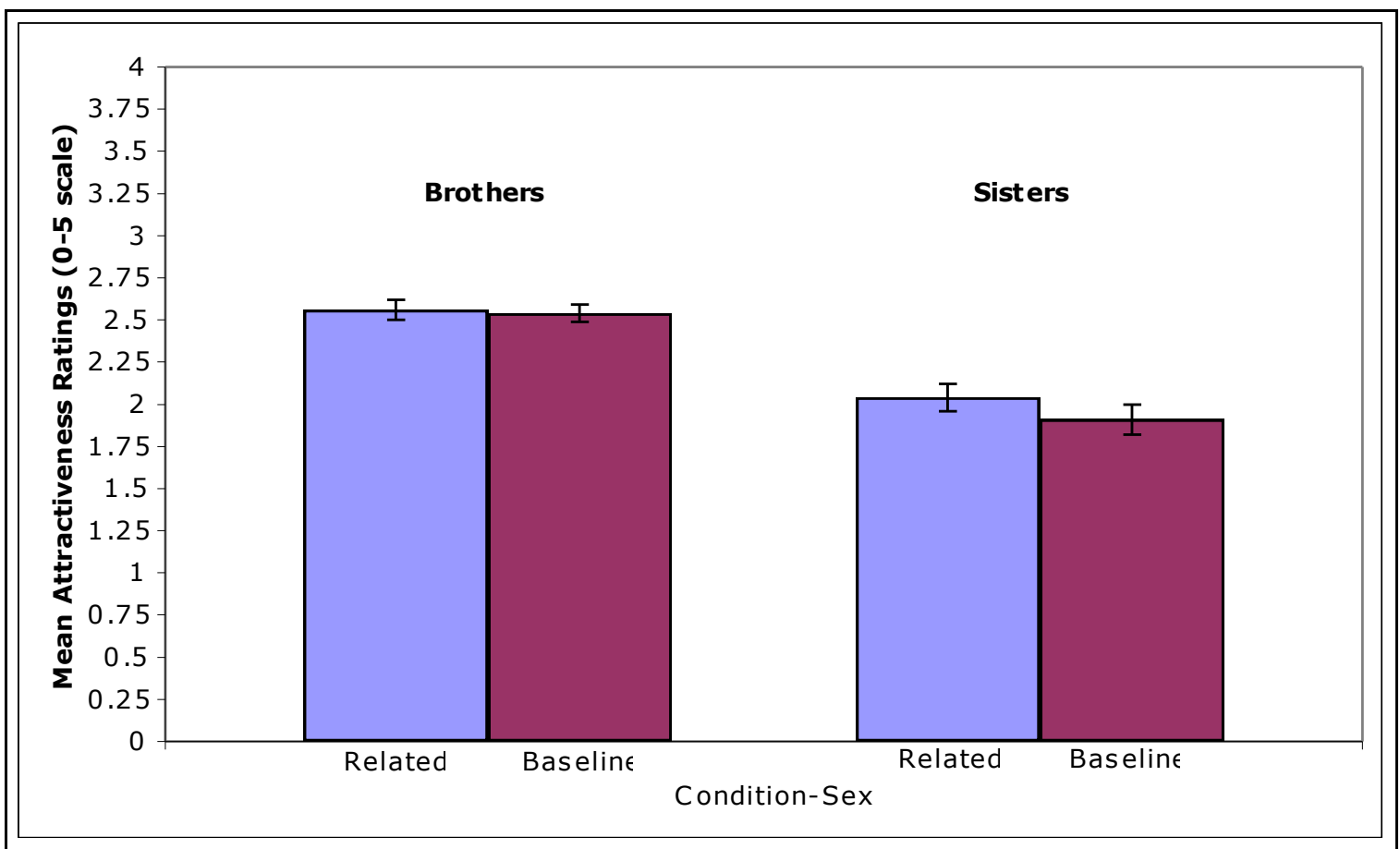

Figure 2. Means and standard errors of male participants' attractiveness ratings for female faces and male faces in the related and baseline conditions. 
related condition $(\mathrm{M}=2.47, \mathrm{sd}=.51)$ surpassed that of the baseline condition $(\mathrm{M}=2.05$, $\left.\mathrm{sd}=.65, \mathrm{~d}^{\prime}=.71\right)$. For the male lows $[\mathrm{t}(62)=4.8, \mathrm{p}<.001]$ the mean of the related condition $(\mathrm{M}=2.09, \mathrm{sd}=.51)$ surpassed that of the baseline condition $\left(\mathrm{M}=1.37, \mathrm{sd}=.62, \mathrm{~d}^{\prime}=1.23\right.$;

Figure 3). For the higher rated female siblings, results were suggestive of an increase but were not statistically significant $[t(62)=1.7, p=.092]$. The mean of the related condition $(\mathrm{M}=2.76, \mathrm{sd}=.57)$ surpassed that of the baseline condition $\left(\mathrm{M}=2.48, \mathrm{sd}=.68, \mathrm{~d}^{\prime}=.44\right)$. However, for the female lows $[\mathrm{t}(62)=2.89, \mathrm{p}=.005]$ the mean of the related condition $(\mathrm{M}=2.32, \mathrm{sd}=.61)$ surpassed that of the baseline condition $\left(\mathrm{M}=1.81, \mathrm{sd}=.73, \mathrm{~d}^{\prime}=.75\right)$ with statistical significance (Figure 4).

Since there were no overall significant effects for male participants, no subsequent analyses were performed. 


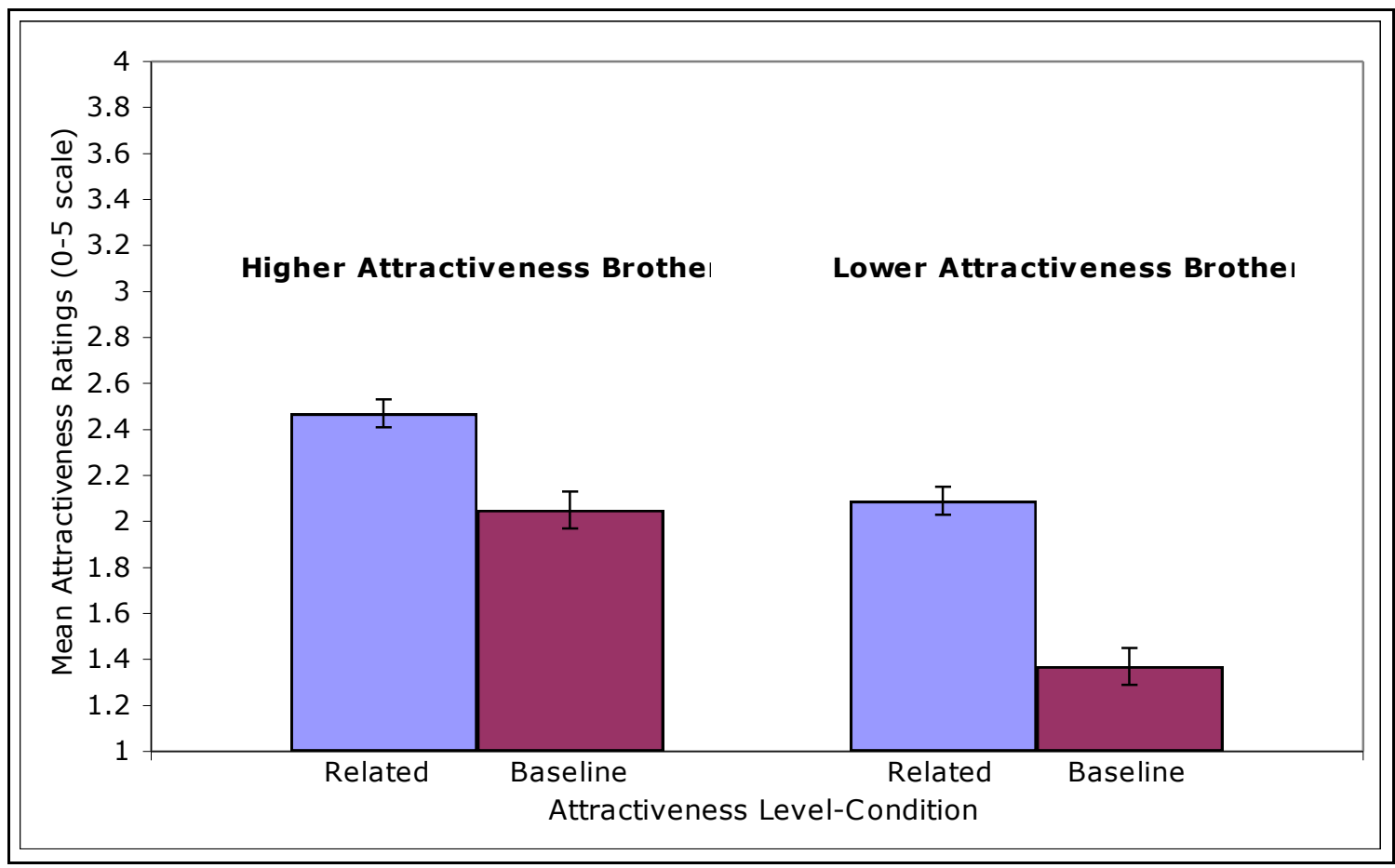

Figure 3. Means and standard errors of female participants' attractiveness ratings for the high attractiveness male faces and low attractiveness male faces in the related and baseline conditions. 


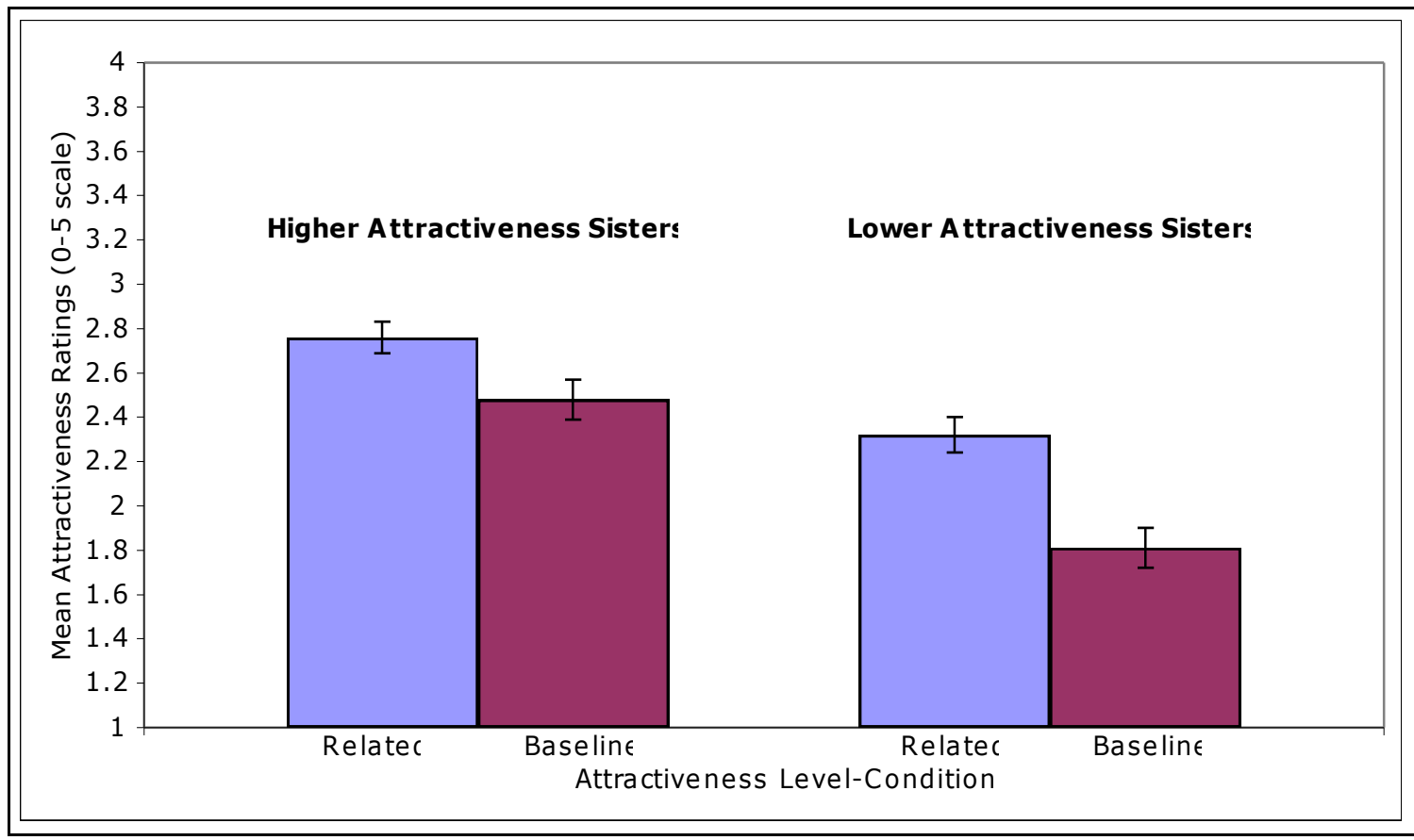

Figure 4. Means and standard errors of female participants' attractiveness ratings for the high attractiveness female faces and low attractiveness female faces in the related and baseline conditions. 


\section{DISCUSSION}

The hypothesis that siblings influence judgments of physical attractiveness was supported by the current study. Though it was shown that this effect was present for both male and female siblings, it appears to be relevant only for female raters. Analyses showed that relatedness significantly affected female judgments of the facial attractiveness for both brothers and sisters, but male judgments of facial attractiveness appeared to be uninfluenced by relatedness for all cases. In fact, male ratings of the physical attractiveness of male and female faces remained nearly identical for both conditions.

Despite these findings, the hypothesis that high and low sibling attractiveness would affect each other in the direction of an average failed to reject the null hypothesis. The null hypothesis was supported for male raters since, as mentioned above, their judgments of attractiveness seemed to remain unaffected by sibling relatedness. Female raters also failed to reject the null hypothesis in that the directionality of the effect of relatedness on sibling attractiveness increased for both high and low attractiveness groupings rather move toward an average for sibling pairs. Thus, when relatedness is factored into attraction judgments it appears to increase the attractiveness for both siblings regardless of potential differences in genetic quality between them.

Parental investment differences between males and females may account for these results in two possible ways. For one, the increased significance of relatedness on female judgments of male facial attractiveness suggests that redundant signals of genetic quality are indeed occurring, but perhaps in relation to reproductive health more so than simply the ability to produce physically attractive traits. It may be supposed that the fact that a 
target mate has a sibling is indicative of parental fertility and genes increasing fertility would be inherited by their offspring (i.e. the target mate). Selecting a fertile male would increase her reproductive success and thereby pass on good genes related to reproductive health to her offspring (Waynforth, 1998). Furthermore, the presence of siblings may indicate good genes associated to viability because the presence of a sibling infers that he or she is currently alive and has, depending on the age, survived to reproductive maturity. Historically, this would have been a potent indication of good fitness due to the high morality rate typical of traditional human societies (Buss, 2005; Migliano, Vinicius, \& Lahr, 2007).

Because women stand to lose more by choosing an infertile mate or a mate with poor genetic quality than men in terms of time lost for her own fertility (Buss, 2005), women may be more likely to assess good genes related to fertility and offspring viability through the presence of multiple siblings when choosing a mate. This may be supported by the findings that women, more so than men, employ a long-term mate strategy (Buss $\&$ Schmitt, 1993) requiring an assessment for more attributes of mate quality (Cunningham et al., 1990; Todd et al., 2007) in order to balance preferences between good genes and good paternal investment (Jones et al., 2008) so as to mitigate their greater investment requirement towards offspring viability.

Because males have to commit less time and physical resources towards offspring viability in order to achieve reproductive success (Trivers, 1972), it is not surprising that relatedness has nearly no effect on their judgments of physical attractiveness. Though males would incur costs towards time and resources for selecting a mate of poorer quality, these do not necessarily reduce their reproductive potential since males remain 
fertile to an older age than females (Buss, 2005). Historically, males need only participate in the sexual act and can refocus mating efforts towards another female fairly quickly, and thereby increase reproductive success by way of multiple progeny with multiple women. Indeed, research on male mating tendencies towards a preference for sexual variety (Clarke \& Hatfield, 1989) and general utilization of short-term mating strategies (Buss \& Schmitt, 1993) uphold this conclusion. Physical traits are still assessed for fertility, but in a short-term strategy, where sexual availability is more important than quality certainty (Buss \& Schmitt, 1993), it would be less costly to accidentally select an infertile short-term mate and move on. While males overwhelmingly prefer a physically attractive mate (Buss, 2003; Rhodes, 2006; Todd et al., 2007) over other aspects of mate quality, and physical attractiveness is indicative of genetic quality, it would appear that males need no further indications of quality other than what the target mate provides. That is, the current study suggests that when it comes to male judgments of female facial attractiveness, it would appear that you either "have the goods," so to speak, or you do not.

However, a second explanation that aligns with parental investment theory pertains to the increased support a person would receive from the kin of one's mate and this may be more relevant as to why relatedness significantly affects women's judgments of attractiveness more so than men's. In line with this proposition and with the data from the current study, females would benefit most from relatedness factors when considering a potential mate. Women's increased parental investment costs would be mitigated by the social/familial benefits siblings would provide. According to Kin Selection theory (Hamilton, 1963), many pro-social and altruistic human behaviors are focused towards 
those with similar genes, as determined through physical cues, and this is especially potent for those directly related to each other. Because of this, it is beneficial to look after the well-being of those individuals because it increases the probability that these shared genes will perpetuate through human procreation. In support of this, DeBruine (2002, 2004) found that similarity in faces enhances trust and increases the physical attractiveness of same-sex others, which influences social behaviors and cooperation (Kahn et al., 1971).

Inclusive Fitness extends kin selection logic to include those not necessarily related to each other as "kin," though altruistic, cooperative, or fitness-reducing behaviors diminish the further from relatedness a person is since there are fewer similar shared genes that would enjoy a fitness advantage (DeBruine, Jones, Little, \& Perrett, 2008; Rushton, 2009). Relating to the current study, women may increase reproductive success and reduce the costs of parental investment through the selection of a mate with siblings. Because of kin selection behaviors, her offspring will most likely benefit from increased resource investment and protection provided by aunts or uncles. In line with Inclusive Fitness theory, she herself may also gain direct benefits from her mate's kin simply because in providing for her they help ensure some of their genes are passed on through her offspring (Fortunato \& Archetti, 2010).

Indeed, much of the conflict between daughters and parents regarding mate selection may be due to mating tradeoffs inherent with the increased parental investment women face (Buunk, Park, \& Dubbs, 2008), with parents wanting a mate most advantageous for kin selection purposes (e.g. a male displaying cues of resources and a willingness towards paternal investment) and daughters wanting a mate who will provide 
good genes (e.g. physically attractive males). In line with the data from the current study, the effect of relatedness on female's judgments of facial attractiveness of both high and low attractiveness males may be due to the advantage provided in terms of potentially obtaining increased support and protection through inclusive fitness.

Males of high attractiveness with siblings look better because they provide evidence for both good genes and potentially increased investment from kin. Males of low attractiveness improve because they at least may be able to provide additional support for offspring through family associations. Because women show a primary mate preference towards males who have the potential to acquire and invest resources (Buss, 1989; Escasa et al., 2010; Todd et al., 2007), it may not be surprising that lesser attractive brothers show a significant increase in perceived attractiveness due to sibling relatedness. This also aligns with Li et al. (2002), who found that low social level was the "deal breaker" for female preferences in a potential mate. Furthermore, a potential mate with a brother would have historically been beneficial since they would have provided increased physical protection for a female and her offspring. Puts (2010) suggests that male coalitions formed almost specifically for this reason, whether they be for acquiring resources through war or discouraging other males from attacking their kin or mates.

The social benefits of selecting a mate with siblings discussed above are further supported by the current study's finding that relatedness increases women's attractiveness ratings of sisters, though not as much as their ratings for brothers. Similar to the less attractive brothers, less attractive sisters significantly increased in attractiveness when relatedness was factored into attraction judgments, suggesting that they would provide similar benefits in terms of increased support through kin selection. Interestingly, unlike 
the more attractive brothers, the more attractive sisters did not significantly increase in attractiveness with relatedness, suggesting that it may be indeed be the case that highly attractive brothers provide an increased bonus of potential good genes as well as kin selection support.

$\underline{\text { Limitations/Delimitations }}$

This study used actual, unaltered photos of male and female faces. Though these offer more ecological validity (Mealy et al., 1999), picture quality and slight differences in pose could affect perceived attractiveness. Differential quality of the picture could influence attraction differences rather than an actual rating of attractiveness. However, this may not be a realistic confounding factor for this study due to the focus on the effect of differential perceived attractiveness between siblings rather than personal perceptions of attractiveness and its covariates. Also, because baseline group photos and related group photos were identical, any confounding factor picture quality had on attraction judgments would have been held constant and thereby be controlled for when analyzing attractiveness differences.

Physical attractiveness was measured specifically for faces, though other factors, such as body types, would still be applicable to attraction ratings (Dixson et al., 2003; Singh, 1993). Eliminating body types from evaluations of physical attractiveness could therefore limit judgments of overall physical attractiveness. However, Peters et al. (2007) suggest that faces independently contribute reliable information about genetic quality and may be even more essential in physical attraction judgments than bodies. Furthermore, limiting judgments to one aspect of physical attraction eliminate other confounding 
factors that have been shown to alter attraction judgments, such as color (Elliot \& Niesta, 2008) or fashion (Sefcek et al., 2006).

The current study used same sex sibling pairs. Because of human sex differences in facial morphology, it was reasonable to limit this study to same sex faces in order to explore possible interactions between attractiveness and relatedness since same sex siblings provide redundant sex-specific physical traits (Johnston et al., 2001). However, it would be reasonable to use opposite sex siblings since the same underlying condition is necessary to produce either male or female traits. Furthermore, the current study also limited the number of siblings to pairs. Though this was reasonable for this particular study, according to the redundant and multiple signal theories more information is better, and thus attractiveness comparisons between multiple siblings could prove to be a significant factor in judgments of mate quality.

A potentially major limitation of this study was the indiscriminate use of the word "attractive" in the instructions. It was assumed that because the stimuli were limited to male and female faces without any further information provided it would imply that participants would judge "attractiveness" in terms of physical attractiveness. Attraction is a broad category and sexual attraction is one factor geared specifically for mating behaviors (Sugiyama, 2005). If "attraction" was not used precisely, then it could be unclear if participants were rating physical attractiveness, group attractiveness, friendship attractiveness, etc. Despite this concern, the speed at which participants viewed target faces as well as the limited information provided most likely limited participant responses to ratings of physical attractiveness (Lenton \& Francesconi, 2010). As Kurzban and Weeden (2005) showed, physical attractiveness is the most salient domain of attraction 
when time is limited in attractiveness evaluations of potential mates and would therefore limit participants to distinctly evaluate physical attractiveness. The limited time and information provided in the current study thereby maintained the construct validity despite the indiscriminate use of "attractive."

Instrument design might have posed as a limitation in terms of ceiling and floor effects. Though it is supposed that a smaller Likert scale is effective in capturing accurate attractiveness-related ratings (Dixson et al., 2010), this may have presented a sensitivity problem when using siblings as targets. Because siblings, despite some genetic variation, are usually similar in appearance (DeBruine et al., 2008), the use of a smaller rating scale may not provide enough numerical variation to show true differences in attractiveness, thus increasing the probability of Type II error. The use of a larger scale (e.g. 10-point Likert scale) may be more effective in showing actual differences in attractiveness ratings. For example, the difference between a sibling rated as a " 3 " and a sibling rated as a "4" appears minimal when using a 6-point scale, but these same siblings may appear as a "4" and a "9" respectively when a 10-point scale is used, and therefore allow for a clearer difference between sibling attractiveness to be analyzed. It may also be beneficial to use a balanced scale in which the number of negative ratings match the number of positive ratings (e.g. $0=$ "very unattractive" and $10=$ "very attractive") since this may be more relevant to the actual semantics humans use when making attractiveness judgments than using a primarily positive scale.

Another limitation in experimental design was the use of 40 individual sibling target faces. It would be analytically advantageous to observe the changes in attractiveness ratings apparent between each individual face and his or her sibling since 
this would allow a greater degree of certainty in observations of directionality. However, to counter-balance for 40 individual sequential faces requires a 40 factorial design, and therefore was unrealistic for the current study to undertake. Thus, the current study counter-balanced between high versus low attractiveness sibling groupings and was able to gain a general analysis of the significance and directionality of the effect relatedness has on sibling physical attractiveness ratings, which was a reasonable limitation for an initial exploration of this hypothesis.

External validity was limited due to sampling, which consisted primarily of undergraduate university students, so conclusions must be limited to this demographic. Furthermore, all target faces were of Caucasian brothers and sisters, which limit generalizations to this target population.

\section{$\underline{\text { Future Directions }}$}

In order to remedy some limitations previously mentioned, future studies could provide more specific qualifications for attraction judgment parameters (e.g. physical attractiveness), add mating strategy as a factor, and use a larger rating scale. One study could have participants rate target faces in terms of long-term versus short-term mate preferences (Buss \& Schmitt, 1993). By using sexual strategies as a qualifier one could simultaneously explore relatedness effects on mating strategies as well as clearly imply sexual attraction as the context for attraction judgments. To limit floor and ceiling effects, using a 10-point Likert scale could provide more accurate analysis. Also, using fewer sibling pairs, one or two for each sex perhaps, would allow for a more reasonable reversed counter-balanced design capable of analyzing the effects of attractiveness differences between siblings on each other. In this way, the strength and directionality of 
the effect low and high attractiveness have on each other when rating siblings can be analyzed. The current study was limited to a more general analysis and the data suggest a further exploration into this effect would be fruitful.

Using opposite sex sibling pairs in future studies could explore the possibility that relatedness offers different and similar benefits for reproductive success depending on the gender of the sibling. Because of the potential for reducing costs of parental investment while simultaneously gaining good genes for offspring, mixed gender sibling pairs may show a significant increase in attractiveness ratings for female raters and the directionality of such influences could be further explored.

It is possible that more siblings would be better in terms of inclusive fitness benefits as well as potentially increasing the redundancy of physically attractive traits. Also, the number of siblings and even the size of a target mate's family may be indicative of good genes related to reproductive health and viability. Thus, expanding the number of siblings used in stimuli could examine the possibility that sibling number would significantly affect attractiveness judgments. If resources permit, any conclusions about genetic quality differences between siblings could be confirmed through the use of genetic testing as well as longitudinal studies focusing on longevity and fertility outcomes.

Furthermore, it must be stated that evolutionary genetics involves much more than the simplistic conceptualization provided in this study on both an environmental and a molecular level with Mendelian genetics simply acting as basic laws of heritability (Dobzhansky, 1965). Genetic quality, when taken in the context of the intricate interactions of thousands of alleles, is a complex term and denotes an intricate 
involvement of multiple genes, as well as environment-gene interactions, that affect the development of fitness-related traits (Houle, 1991). Though this study defined genetic quality as the basis of sexually attractive trait development, further research is necessary to continue to explore the effect of genetic quality on other fitness-related aspects of mate quality as many of the biological mechanisms linking the two remain somewhat of a mystery (Gangestad \& Scheyd, 2005).

In addition to the complexity of genetic influences on human behavior is the role of culture and environment. Though the conclusions of this study rely heavily on generalized biological influences in human mating behaviors, observations of actual mating behaviors may show environment-specific differences between cultures, due to familial, societal, and individual beliefs about sex-roles and sexual behaviors, that do not easily conform to evolutionary psychological assumptions (e.g. sexual strategies, parental investment; Sugiyama, 2005). Indeed, Buss (2009) discusses these concerns and states that though there may be universal tendencies due to selection processes these are continually forced to conform to specific adaptive problems faced by men and women within their environmental and cultural contexts. Buss continues by admitting that evolutionary psychology is relatively young as a psychological framework and is therefore limited in its explanations and explorations of many psychological phenomena associated with human behaviors. Further studies using evolutionary predictions based on specific environmental and cultural needs that focus on actual mating behaviors across the lifespan (e.g. Life-History Theory; Kaplan \& Gangestad, 2005) would help to add validity to many assumptions posited by evolutionary psychology and biology. 
Also related to cultural considerations, a level of universality is assumed in many attraction studies using an evolutionary psychological framework and this is justified with the current research (Buss, 1989; Dixson et al., 2003; Getty, 2002; Jones et al., 1995; Rhodes, 2006; Schmitt et al., 2003). Because physical attraction appears to be an important factor in mate quality judgments across cultures (Barber, 1995; Buss, 1989; Cunningham et al., 1995; Fink \& Penton-Voak, 2002; Jones et al., 1995) and relates to genetic quality (Burt, 1995; Grammer et al., 2003; Jones et al., 2001; Lie et al., 2008), effects of relatedness on attraction ratings should be present across the human species due to the advantage it may provide to reproductive success. The use of racially diverse target faces as well as a more culturally diverse sample would provide potential external validity support and offer further examination of relatedness' affect on attraction preferences that may be culturally/environmentally specific.

Overall, relatedness could prove a fertile area of research for multiple factors of mate quality influences. Future studies could explore sibling influences on other areas of mate quality, such as: attractive body morphologies (Peters et al., 2007), attitude similarity (Kleck \& Rubenstein, 1975), and social status (Buss, 2005). For example, intelligence is considered heritable and may be a significant factor in judgments of status and ability to consistently invest resources (Zebrowitz \& Rhodes, 2004) and a study may use measures of IQ of related individuals as a factor of comparison in mate attractiveness judgments. Another study could examine if sibling mental health status affects attraction judgments. Similarly, using fashion and grooming as a factor indicative of status, one could examine if siblings displaying consistent cues in this domain affect overall attraction ratings. 
The importance of such explorations would be that if relatedness seems to indeed play a functional role in other factors of mate quality, it could potentially imply that humans have an innate understanding of evolution and be conscious of the heritable benefits of genetic quality towards other fitness-related factors of mate quality (e.g. intelligence, emotional stability). Gangestad and Scheyd (2005) discuss the hesitancy of psychology researchers in examining the genetic underpinnings of human behaviors, including mating behaviors. Studies using relatedness as a factor of analysis offer an avenue to explore this complex relationship and may yet provide insights into the interactions between biology, environment, and human cognition that compose the intricacies of human psychology. 
Appendix A

Attractiveness Rating Sheet (Female Side Only)

\begin{tabular}{|c|c|c|c|c|c|c|}
\hline Female & UNATTRACTIVE & $\begin{array}{l}\text { ONLY } \\
\text { SLIGHTLY } \\
\text { ELTRACTIVE }\end{array}$ & $\begin{array}{l}\text { MILDLY } \\
=\text { ATTRACTIVE }\end{array}$ & $\begin{array}{l}\text { MODERATELY } \\
\text { ATTRACTIVE }\end{array}$ & \begin{tabular}{|l} 
VERY \\
ATTRACTIVE
\end{tabular} & \begin{tabular}{|l} 
EXTREMELY \\
ATTRACTIVE
\end{tabular} \\
\hline$A$ & o & 1 & 2 & 3 & 4 & 5 \\
\hline$B$ & 0 & 1 & 2 & 3 & 4 & 5 \\
\hline$C$ & $\mathbf{0}$ & 1 & 2 & 3 & 4 & 5 \\
\hline$D$ & 0 & 1 & 2 & 3 & 4 & 5 \\
\hline$E$ & 0 & 1 & 2 & 3 & 4 & 5 \\
\hline$F$ & 0 & 1 & 2 & 3 & 4 & 5 \\
\hline$G$ & 0 & 1 & 2 & 3 & 4 & 5 \\
\hline$H$ & $\mathbf{0}$ & 1 & 2 & 3 & 4 & 5 \\
\hline$I$ & $\mathbf{0}$ & 1 & 2 & 3 & 4 & 5 \\
\hline$J$ & 0 & 1 & 2 & 3 & 4 & 5 \\
\hline$K$ & 0 & 1 & 2 & 3 & 4 & 5 \\
\hline$L$ & 0 & 1 & 2 & 3 & 4 & 5 \\
\hline$M$ & 0 & 1 & 2 & 3 & 4 & 5 \\
\hline$N$ & 0 & 1 & 2 & 3 & 4 & 5 \\
\hline$O$ & 0 & 1 & 2 & 3 & 4 & 5 \\
\hline$P$ & 0 & 1 & 2 & 3 & 4 & 5 \\
\hline$Q$ & 0 & 1 & 2 & 3 & 4 & 5 \\
\hline$R$ & 0 & 1 & 2 & 3 & 4 & 5 \\
\hline$S$ & $\mathbf{0}$ & 1 & 2 & 3 & 4 & 5 \\
\hline$T$ & $\mathbf{0}$ & 1 & 2 & 3 & 4 & 5 \\
\hline $\begin{array}{l}\text { Major: } \\
\text { Sex: } \\
\text { Age: } \\
\text { What is your race and/or eth } \\
\quad \text { African American/Black } \\
\text { Asian/Asian American } \\
\text { Caucasian/White } \\
\text { Latina/o } \\
\text { American Indian/Native } \\
\text { Middle Eastern/Persian } \\
\end{array}$ & $\begin{array}{l}\text { icity: } \\
\text { nerican }\end{array}$ & & $\begin{array}{c}\text { _ Multiraci } \\
\text { OOther: }\end{array}$ & ial/Biracial: & & \\
\hline
\end{tabular}


Appendix B

Pilot Rating Sheet

Gender

Age

Please Circle the MORE attractive sibling

Females

$\begin{array}{ll}\text { A } & \text { B } \\ \text { C } & \text { D } \\ \text { E } & \text { F } \\ \text { G } & \text { H } \\ \text { I } & \text { J } \\ \text { K } & \text { L } \\ \text { M } & \text { N } \\ \text { O } & \text { P } \\ \text { Q } & \text { R } \\ \text { S } & \text { T }\end{array}$

Males

$\begin{array}{ll}\text { A } & \text { B } \\ \text { C } & \text { D } \\ \text { E } & \text { F } \\ \text { G } & \text { H } \\ \text { I } & \text { J } \\ \text { K } & \text { L } \\ \text { M } & \text { N } \\ \text { O } & \text { P } \\ \text { Q } & \text { R } \\ \text { S } & \text { T }\end{array}$




\section{Bibliography}

Barber, N. (1995). The evolutionary psychology of physical attractiveness: sexual selection and human morphology. Ethology and Sociobiology, 16, 395-424.

Bereczkei, T., \& Csanaky, A. (1996). Mate choice, marital success, and reproduction in a modern society. Ethology and Sociobiology, 17(1), 17-35.

Blouin, S.F., \& Blouin, M. (1988). Inbreeding avoidance behaviors. Trends in Ecology and Evolution, 3(9), 230-233.

Burt, A. (1995). Perspective: The evolution of fitness. Evolution, 49, 1-8.

Buss, D.M. (1984). Marital assortment for personality dispositions: Assessment with three different data sources. Behavior Genetics, 14(2), 111-123.

Buss, D.M. (1988). The evolution of human intrasexual competition: Tactics of mate attraction. Journal of Personality and Social Psychology, 54(4), 616-628.

Buss, D.M. (1989). Sex differences in human mate preferences: Evolutionary hypotheses tested in 37 cultures. Behavioral and Brain Sciences, 12, 1-14.

Buss, D.M. (1995). Evolutionary psychology: A new paradigm. Psychological Inquiry, 6, $1-30$.

Buss, D.M. (2003). The evolution of desire: Strategies of human mating. ( $4^{\text {th }} \mathrm{ed}$.). New York: Basic Books.

Buss, D.M. (2005). The handbook of evolutionary psychology. New Jersey: Wiley \& Sons, Inc.

Buss, D.M. (2007). The Evolution of Human Mating Strategies: Consequences for Conflict and Cooperation. In S.W. Gangestad \& J.A. Simpson (Eds.), The evolution of mind: Fundamental questions and controversies (pp. 375-382). New 
York: Guilford Press.

Buss, D.M. (2009). How can evolutionary psychology successfully explain personality and individual differences? Perspectives on Psychological Science, 4, 359-366, doi: 10.1111/j.1745-6924.2009.01138.x

Buss, D.M., \& Schmitt, D.P. (1993). Sexual strategies theory: An evolutionary perspective on human mating. Psychological Review, 100, 204-232.

Buunk, A.P., Park, J.H., \& Dubbs, S.L. (2008). Parent-offspring conflict in mate preferences. Review of General Psychology, 12, 47-62, doi: 10.1037/10892680.12.1.47

Carré, J.M., McCormick, C.M., \& Mondloch, C.J. (2009). Facial structure is a reliable cue of aggressive behavior. Psychological Science, 20, 1194-1198.

Cavior, N., \& Dokecki, P.R. (1973). Physical attractiveness, perceived attitude similarity, and academic achievement as contributors to interpersonal attraction among adolescents. Developmental Psychology, 9(1), 44-54.

Clarke, G. (1998). The genetic basis of developmental stability. V. Inter- and intraindividual character variation. Heredity, 80, 562-567.

Clarke, R.D., \& Hatfield, E. (1989). Gender differences in receptivity to sexual offers. Journal of Psychology and Human Sexuality, 2, 39-55.

Cornwell, R., \& Perrett, D. (2008). Sexy sons and sexy daughters: the influence of parents' facial characteristics on offspring. Animal Behavior, 76, 1843-1853, doi: 10.1016/j.anbehav.2008.07.031

Cosmides, L., \& Tooby, J. (1989). The innate versus the manifest: How universal does universal have to be? Behavioral and Brain Sciences, 12, 36-37. 
Cosmides, L., Barrett, H.C., \& Tooby, J. (2010). Adaptive specializations, social exchange, and the evolution of human intelligence. Proceedings of the National Academy of Sciences of the United States of America, 107(2), 9007-9014, doi: 10.1073/pnas.0914623107

Cunningham, M.R., Barbee, A.P., \& Pike, C.L. (1990). What do women want? Facialmetric assessment of multiple motives in perception of male facial physical attractiveness. Journal of Personality and Social Psychology, 59(1), 61-72.

Cunningham, M., Roberts, A., Barbee, A., Druen, P., \& Wu, C.H. (1995). 'Their ideas of beauty are, on the whole, the same as ours': consistency and variability in the cross-cultural perception of female physical attractiveness. Journal of Personality and Social Psychology, 68(2), 261-279.

Darwin, C. (1871). The descent of man and selection in relation to sex. New York: Random House.

DeBruine, L.M. (2002). Facial resemblance enhances trust. Proceedings of the Royal Society B: Biological Sciences, 269, 1307-1312.

DeBruine, L.M. (2004). Facial resemblance increases the attractiveness of same-sex faces more than other-sex faces. Proceedings of the Royal Society B: Biological Sciences, 271, 2085-2090.

DeBruine, L.M., Jones, B.C., Little, A.C., \& Perrett, D.I. (2008). Social perception of facial resemblance in humans. Archives of Sexual Behavior, 37, 64-77, doi: $10.1007 / \mathrm{s} 10508-007-9266-0$

Dion, K.K. (1973). Young children's stereotyping of facial attractiveness. Developmental Psychology, 9(2), 183-188, roi: 10.1037/h0035083 
Dion, K., Berscheid, E., \& Walster, E. (1972). What is beautiful is good. Journal of Personality and Social Psychology, 24(3), 285-290.

Dixson, B., Sagata, K., Linklater, W., \& Dixson, A. (2010). Male preferences for female waist-to-hip ratio and body mass index in the highlands of papua new guinea. American Journal of Physical Anthropology, 141(4), 620-65.

Dixson, A.F., Halliwell, G., East, R., Wignarajah, P., \& Anderson, M. (2003). Masculine somatotype and hirsuteness as determinants of sexual attractiveness to women. Archives of Sexual Behavior, 32(1), 29-39.

Dobzhansky, T. (1965). Mendelism, Darwinism, and evolutionism. Proceedings of the American Philosophical Society, 109(4), Commemoration of the Publication of Gregor Mendel's Pioneer Experiments in Genetics, 205-215.

Duchaine, B., Cosmides, L., \& Tooby, J. (2001). Evolutionary psychology and the brain. Current Opinion in Neurobiology, 11, 225-230.

Elliot, A.J., \& Niesta, D. (2008). Romantic red: Red enhances men's attraction to women. Journal of Personality and Social Psychology, 95(5), 1150-1164, doi: $10.1037 / 0022-3514.95 .5 .1150$

Escasa, M., Gray, P.B., \& Patton, J.Q. (2010). Male traits associated with attractiveness in Conambo, Ecuador. Evolution and Human Behavior, 31, 193-200, doi: 10.1016/j.evolhumbehav.2009.09.008

Fink, B., \& Penton-Voak, I. (2002). Evolutionary psychology of facial attractiveness. Current Directions in Psychological Science, 11, 154-158, doi: 10.1111/14678721.00190 
Fink, B., Grammer, K., \& Matts, P.J. (2006). Visible skin color distribution plays a role in the perception of age, attractiveness, and health in female faces. Evolution and Human Behavior, 27, 433-442.

Fiore, A.T. \& Donath, J.S. (2005). Homophiliy in online dating: when do you like someone like yourself? Computer-Human Interaction 2005, 1371-1374.

Fiore, A.T., Taylor, L.S., Mendelsohn, G.A., \& Hearst, M. (2008). Assessing attractiveness in online dating profiles. Computer-Human Interaction 2008, 797 806.

Fisher, R.A. (1915). The evolution of sexual preferences. The Eugenics Review, 7(3), 184-192.

Fisher, R.A. (1918). The correlation between relatives on the supposition of Mendelian inheritance. Transactions of the Royal Society of Edinburgh, 52, 399-433.

Fisman, R., Iyengar, S.S., Kamenica, E., \& Simonson, I. (2006). Gender differences in mate selection: Evidence from a speed dating experiment. The Quarterly Journal of Economics, 121(2), 673-697.

Folstad, I., \& Karter, A. (1992). Parasites, bright males, and the immunocompetence handicap. The American Naturalist, 139(3), 603-622.

Fortunato, L., \& Archetti, M. (2010). Evolution of monogamous marriage by maximization of inclusive fitness. Journal of Evolutionary Biology, 23, 149-156.

Frederick, D.A., \& Haselton, M.G. (2007). Why is muscularity sexy? Tests of the fitness indicator hypothesis. Personality and Social Psychology Bulletin, 33, 1167-1183, doi: $10.1177 / 0146167207303022$ 
Gangestad, S.W., \& Scheyd, G.J. (2005). The evolution of physical attractiveness.

Annual Review of Anthropology, 34, 523-548, doi:

10.1146/annurev.anthro.33.070203.143733

Gangestad, S.W., \& Thornhill, R. (2003). Facial masculinity and fluctuating asymmetry. Evolution and Human Behavior, 24, 231-241, doi: 10.1016/S10905138(03)00017-5

Gangestad, S.W., Haselton, M.G., \& Buss, D.M. (2006). Evolutionary foundations of cultural variation: Evoked culture and mate preferences. Psychological Inquiry, $17(2), 75-95$.

Gangestad, S.W., Thornhill, R., \& Garver-Apgar, C.E. (2005). Adaptations to ovulation: Implications for sexual and social behavior. Current Directions in Psychological Science, 14(6), 312-316, doi: 10.1111/j.0963-7214.2005.00388.x

Gangestad, S., Garver-Apgar, C., Simpson, J., \& Cousins, A. (2007). Changes in womens' mate preferences across the ovulatory cycle. Journal of Personality and Social Psychology, 92(1), 151-163, doi: 10.1037/0022-3514.92.1.151

Garver-Apgar, C.E., Gangestad, S.W., Thornhill, R., Miller, R.D., \& Olp, J.J. (2006). Major histocompatibility complex alleles, sexual responsivity, and unfaithfulness in romantic couples. Psychological Science, 17, 830-835, doi: 10.1111/j.14679280.2006.01789.x

Getty, T. (2002). Signaling health versus parasites. American Naturalist, 159(4), 363371.

Grafen, A. (1990a). Biological signals as handicaps. Journal of Theoretical Biology 144, 517-546. 
Grafen, A. (1990b). Sexual selection unhandicapped by the Fisher process. Journal of Theoretical Biology, 144, 473-516.

Grammer, K., \& Thornhill, R. (1994). Human (Homo sapiens) facial attractiveness and sexual selection: The role of symmetry and averageness. Journal of Comparative Psychology, 108(3), 233-242.

Grammer, K., Fink, B., Møller, A.P., \& Manning, J.T. (2005). Physical attractiveness and health: Comment on Weeden and Sabini (2005). Psychological Bulletin, 131, 568-661, doi: 10.1037/0033-2909.131.5.658

Grammer, K., Fink, B., Møller, A.P., \& Thornhill, R. (2003). Darwinian aesthetics: Sexual selection and the biology of beauty. Biological Reviews, 78, 385-407.

Greiling, H., \& Buss, D.M. (2000). Women's sexual strategies: the hidden dimension of extra-pair mating. Personality and Individual Differences, 28, 929-963.

Hadjistavropoulos, T., \& Genest, M. (1994). The underestimation of the role of physical attractiveness in dating preferences: ignorance or taboo? Canadian Journal of Behavioral Science, 26(2), 298-318.

Hagiwara, S. (1975). Visual versus verbal information in impression formation. Journal of Personality and Social Psychology, 32(4), 692-698.

Hamilton, W.D. (1963). The evolution of altruistic behavior. The American Naturalist, 97(896), 354-356.

Haselton, M.G., Buss, D.M., Oubaid, V., \& Angleitner, A. (2005). Sex, lies, and strategic interference: The psychology of deception between the sexes. Personality and Social Psychology Bulletin, 31(3), 3-23, doi: 10.1177/0146167204271303 
Havlicek, J., Roberts, S.C., \& Flegr, J. (2005). Women's preference for dominant male odour: Effects of menstrual cycle and relationship status. Biology Letters, 1, 256259, doi: $10.1098 / \mathrm{rsbl} .2005 .0332$

Henderson, J.J.A., \& Anglin, J.M. (2003). Facial attractiveness predicts longevity. Evolution and Human Behavior, 24, 351-356.

Houle, D. (1991). Genetic covariance of fitness correlates: what genetic correlations are made and why it matters. Evolution, 45(3), 630-648.

Insko, C.A., Thompson, V.D., Stroebe, W., Shaud, K.F., Pinner, B.E., \& Layton, B.D. (1973). Implied evaluation and the similarity-attraction effect. Journal of Personality and Social Psychology, 25, 297-308.

Jacob, S., McClintock, M.K., Zelano, B., \& Ober, C. (2002). Paternally inherited HLA alleles are associated with women's choice of male odor. Nature Genetics, 30, 175-179, doi: 10.1038/ng830

Johnston, V. S., Hagel, R., Franklin, M., Fink, B., \& Grammer, K. (2001). Male facial attractiveness: Evidence for hormone-mediated adaptive design. Evolution and Human Behavior, 22, 251-267.

Johnstone, R.A. (1995). Honest advertisement of multiple qualities using multiple signals. Journal of Theoretical Biology, 177, 87-97.

Johnstone, R.A., \& Grafen, A. (1993). Dishonesty and the handicap principle. Animal Behavior, 46, 759-764.

Jones, B.C., DeBruine, L.M., Perrett, D.I., Little, A.C., Feinberg, D.R., \& Smith, M.J.L. (2008). Effects of menstrual cycle phase on face preferences. Archives of Sexual Behavior, 37, 78-84, doi: 10.1007/s10508-007-9268-y 
Jones, B.C., Little, A.C., Penton-Voak, I.S., Tiddeman, B.P., Burt, D.M., \& Perrett, D.I. (2001). Facial symmetry and judgments of apparent health: Support for a "good genes" explanation of the attractiveness-symmetry relationship. Evolution and Human Behavior, 22(6), 417-429.

Jones, D., Brace, C., Jankowiak, W., Laland, K., Musselman, L., Langlois, J., Roggman, L., Pe'russe, D., Schweder, B., \& Symons, D. (1995). Sexual selection, physical attraction, and facial neoteny: cross-cultural evidence and implications [and comments and reply]. Current Anthropology, 36(5), 723-748. Retrieved from http://www.jstor.org/stable/27440166

Kahn, A., Hottes, J., \& Davis, W.L. (1971). Cooperation and optimal responding in the prisoner's dilemma game: Effects of sex and physical attractiveness. Journal of Personality and Social Psychology, 17(3), 267-279.

Kalick, S.M., \& Hamilton, T.E. (1986). The matching hypothesis reexamined. Journal of Personality and Social Psychology, 51(4), 673-682.

Kalick, S.M., Zebrowitz, L.A., Langlois, J.H., \& Johnson, R.M. (1998). Does human facial attractiveness honestly advertise health? Longitudinal data on an evolutionary question. Psychological Science, 9, 8-13.

Kaplan, H.S., \& Gangestad, S.W. (2005). Life history theory and evolutionary psychology. In D.M. Buss (Ed.) The Handbook of Evolutionary Psychology (pp. 68-96). New York: Wiley.

Kleck, R.E., \& Rubenstein, C. (1975). Physical attractiveness, perceived attitude similarity, and interpersonal attraction in an opposite-sex encounter. Journal of Personality and Social Psychology, 31, 107-114. 
Kokko, H., Brooks, R., Jennions, M.D., \& Morley, J. (2003). The evolution of mate choice and mating biases. Proceedings of the Royal Society London B: Biolgoical Sciences, 270, 653-664.

Kosova, G., Abney, M., \& Ober, C. (2010). Heritability of reproductive fitness traits in a human population. PNAS, 107(1), 1772-1778.

Kurzban, R., \& Weeden, J. (2005). Hurry date: Mate preferences in action. Evolution and Human Behavior, 26(3), 227-244, doi: 10.1016/j.evolhumbehav.2004.08.012

Lande, R. (1981). Models of speciation by sexual selection on polygenic traits.

Proceedings of the National Academy of Sciences of the United States of America, 78(6), 3721-3725.

Langlois, J.H., Roggman, L.A., \& Rieser-Danner, L.A. (1990). Infants' differential social responses to attractive and unattractive faces. Developmental Psychology, 26, 153-159.

Langlois, J. H., Roggman, L. A., Casey, R. J., \& Ritter, J. M. (1987). Infant preferences for attractive faces: Rudiments of a stereotype? Developmental Psychology, 23, $363-369$

Langlois, J.H., Kalakanis, L., Rubenstein, A.J., Larson, A., Hallam, M., \& Smoot, M. (2000). Maxims or myths of beauty? A meta-analytic and theoretical review. Psychological Bulletin, 126(3), 390-423.

Lee, L., Loewenstein, G., Ariely, D., Hong, J., \& Young, J. (2008). If I'm not hot, are you hot or not? Physical-attractiveness evaluations and dating preferences as a function of one's own attractiveness. Psychological Science, 19, 669-677, doi: 10.1111/j.1467-9280.2008.02141.x 
Lenton, A.P., \& Francesconi, M. (2010). How humans cognitively manage an abundance of mate options. Psychological Science, 21, 528-534, doi: $10.1177 / 0956797610364958$

Li, N.P., Balley, J.M., Kenrick, D.T., \& Linsenmeier, J.A.W. (2002). The necessities and luxuries of mate preferences: Testing the tradeoffs. Journal of Personality and Social Psychology, 82(6), 947-955, doi: 10.1037/0022-3514.82.6.947

Lie, H.C., Rhodes, G., \& Simmons, L. (2008). Genetic diversity reveald in human faces. Evolution, 62(10), 2473-2486, doi: 10.1111/j.1558-5646.2008.00478.x

Lie, H.C., Rhodes, G., \& Simmons, L. (2010). Is genetic diversity associated with mating success in humans? Animal Behaviour, 79(4), 903-909, doi: 10.1016/j.evolhumbehav.2009.07.001

Little, A.C., Burt, D.M., Penton-Voak, I.S., \& Perrett, D.I. (2001). Self-perceived attractiveness influences human female preferences for sexual dimorphism and symmetry in male faces. Proceedings of the Royal Society London B: Biological Sciences, 268(1462), 39-44, doi: 10.1098/rspb.2000.1327

Little, A.C., Jones, B.C., Penton-Voak, I.S., Burt, D.M., \& Perrett, D.I. (2002). Partnership status and the temporal context of relationships influence human female preferences for sexual dimorphism in male face shape. Proceedings of the Royal Society London B: Biological Sciences, 269(1496), 1095-1100, doi: 10.1098/rspb.2002.1984

Little, A.C., Jones, B.C., Waitt, C., Tiddeman, B.P., Feinberg, D.R., Perrett, D.I., Apicella, C.L., \& Marlowe, F.W. (2008). Symmetry is related to sexual 
dimorphism in faces: Data across culture and species. PloS ONE, 3(5), e2106, doi: 10.1371/journal.pone.0002106

Lynch, S.M., \& Zellner, D.A. (1999). Figure preferences in two generations of men: The use of figure drawings illustrating differences in muscle mass. Sex Roles, 40, 833843, doi: 10.1023/A:1018868904239

Maner, J., Kenrick, D., Becker, D., Delton, A., Hofer, B., Wilbur, C., \& Neuberg, S. (2003). Sexually selective cognition: beauty captures the mind of the beholder. Journal of Personality and Social Psychology, 85(6), 1107-1120, doi: $10.1037 / 0022-3514.85 .6 .1107$

Mealy, L., Bredgestock, R., \& Townsend, G. (1999). Symmetry and perceived facial attractiveness. Journal of Personality and Social Psychology, 76, 151-158.

Migliano, A.B., Vinicius, L., \& Lahr, M.M. (2007). Life history trade-offs explain the evolution of human pygmies. PNAS, 104(51), 20216-20219.

Miller, G.F., \& Todd, P.M. (1998). Mate choice turns cognitive. Trends in Cognitive Sciences, 2(5), 190-198, doi: 10.1016/S1364-6613(98)01169-3

Mitton, J.B. (1993). Enzyme heterozygosity, metabolism, and developmental stability. Genetica, 89, 47-65.

Møller, A.P., \& Pomiankowski, A. (1993). Fluctuating asymmetry and sexual selection. Genetica, 89, 267-279.

Møller, A.P., \& Thornhill, R. (1997). A meta-analysis of the heritability of developmental stability. Journal of Evolutionary Biology, 10, 1-16, doi: 10.1046/j.1420-9101.1997.10010001.x 
Møller, A.P., \& Thornhill, R. (1998). Bilateral symmetry and sexual selection: a metaanalysis. American Naturalist, 151, 174-192.

Morris, R.D., \& Morris, J.A. (2004). Sexual selection, redundancy and survival of the most beautiful. Journal of Biosciences, 29, 359-366.

Murstein, B.I. (1972). Physical attractiveness and marital choice. Journal of Personality and Social Psychology, 22, 8-12.

Muscarella, F., \& Cunningham, M.R. (1996). The evolutionary significance and social perception of male pattern baldness and facial hair. Ethology and Sociobiology, $17,99-117$.

Neave, N., \& Shields, K. (2008). The effects of facial hair manipulation on female perceptions of attractiveness, masculinity, and dominance in male faces. Personality and Individual Differences, 45(5), 373-377, doi: 10.1016/j.paid.2008.05.007

Neave, N., Laing, S., Fink, B., \& Manning, J.T. (2003). Second to fourth digit ratio, testosterone and perceived male dominance. Proceedings of the Royal Society B: Biolgoical Sciences, 270(1529), 2167-2172, doi: 10.1098/rspb.2003.2502

Neff, B.D., \& Pitcher, T.E. (2005). Genetic quality and sexual selection: An integrated framework for good genes and compatible genes. Molecular Ecology, 14, 19-38, doi: 10.1111/j.1365-294X.2004.02395.x

Ober, C.L., Hauck, W.W., Kostyu, D.D., O’Brien, E., Elias, S., Simpson, J.L., \& Martin, A.O. (1985). Adverse effects of human leukocyte antigen-DR sharing on fertility: a cohort study in a human isolate. Fertility and Sterility, 44(2), 227-232. 
Orr, H.A. (2009). Fitness and its role in evolutionary genetics. National Review Genetics, 10(8), 531-539, doi: 10.1038/nrg2603

Parsons, P.A. (1990). Fluctuating asymmetry: An epigenetic measure of stress. Biological Review, 65, 131-145.

Penke, L., Todd, P.M., Lenton, A.P., \& Fasolo, B. (2007). How self-assessments can guide human mating decisions. In G. Gehr \& G.F. Miller (Eds.), Mating intelligence: New insights into intimate relationships, human sexuality, and the mind's reproductive system (pp. 37-75). Mahwah: Lawrence Erlbaum.

Penton-Voak, I.S. \& Chen, J.Y. (2004). High salivary testosterone is linked to masculine male facial appearance in humans. Evolution and Human Behavior, 25(4), 229241, doi: 10.1016/j.evolhumbehav.2004.04.003

Penton-Voak, I.S., Jacobson, A., \& Trivers, R. (2004). Populational differences in attractiveness judgments of male and female faces: Comparing British and Jamaican samples. Evolution and Human Behavior, 25(6), 355-370, doi: 10.1016/j.evolhumbehav.2004.06.002

Perrett, D.I., May, K.A., \& Yoshikawa, S. (1994). Facial shape and judgments of female attractiveness. Nature, 368, 239-242.

Peters, M., Rhodes, G., \& Simmons, L.W. (2007). Contributions of the face and body to overall attractiveness. Animal Behaviour, 73(6), 937-942, doi:

10.1016/j.anbehav.2006.07.012

Pierce, B. (2008). Genetics: A conceptual approach. (3 ${ }^{\text {rd }}$ ed.). New York: W.H. Freeman and Company. 
Platek, S.M., \& Singh, D. (2010). Optimal waist-to-hip ratios in women activate neural reward centers in men. PLOS One, 5(2), e.9042, doi: 10.1371/journal.pone.0009042

Puts, D.A. (2010). Beauty and the beast: Mechanisms of sexual selection in humans. Evolution and Human Behavior, 31, 157-175, doi: 10.1016/j.evolhumbehav.2010.02.005

Rhodes, G. (2006). The evolutionary psychology of facial beauty. Annual Review of Psychology, 57, 199-226, doi: 10.1146/annurev.psych.57.102904.190208

Rhodes, G., Simmons, L.W., \& Peters, M. (2005). Attractiveness and sexual behavior: Does attractiveness enhance mating success? Evolution and Human Behavior, 26, 186-201, doi: 10.1016/j.evolhumbehav.2004.08.014

Rhodes, G., Sumich, A., \& Byatt, G. (1999). Are average facial configurations attractive only because of their symmetry? Psychological Science, 10, 52-58.

Rhodes, G., Chan , J., Zebrowitz, L.A., \& Simmons, L.W. (2003). Does sexual dimorphism in human faces signal health? Proceedings of the Royal Society London B: Biological Sciences, 270, S93-S95, doi: 10.1098/rsbl.2003.0023

Rhodes, G., Zebrowitz, L.A., Clark, A., Kalick, S.M., Hightower, A., \& McKay, R. (2001). Do facial averageness and symmetry signal health? Evolution and Human Behavior, 22(1), 31-46.

Roberts, M.L., Buchanan, K.L., \& Evans, M.R. (2004). Testing the immunocompetence handicap hypothesis: A review of the evidence. Animal Behavior, 68, 227-239.

Roberts, S.C., \& Little, A.C. (2008). Good genes, complementary genes and human mate preferences. Genetica, 134, 31-43, doi: 10.1007/s10709-008-9254-x 
Roberts, S.C., Little, A.C., Gosling, L.M., Jones, B.C., Perrett, D.I., Carter, V., \& Petrie, M. (2005a). MHC-assortative facial preferences in humans. Biology Letters, 1, 400-403, doi: 10.1098/rsbl.2005.0343

Roberts, S.C., Little, A.C., Gosling, L.M., Perrett, D., Carter, V., Jones, B.C., PentonVoak, I., \& Petrie, M. (2005b). MHC-heterozygosity and human facial attractiveness. Evolution and Human Behavior, 26(3), 213-226.

Rowe, L., \& Houle, D. (1996). The lek paradox and the capture of genetic variance by condition dependent traits. Proceedings of the Royal Society London B:

Biological Sciences, 263, 1415-1421.

Rushton, J., \& Bons, T.A. (2005). Mate choice and friendship in twins: evidence for genetic similarity. Psychological Science, 16(7), 555-559.

Rushton, J. (2009). Inclusive fitness in human relationships. Biological Journal of the Linnean Society, 96, 8-12, doi: 10.1111/j.1095-8312.2008.01110.x

Salter, F. (1996). Carrier females and sender males: An evolutionary hypothesis linking, female attractiveness, family resemblance, and paternity confidence. Ethology and Sociobiology, 17, 211-220.

Samson, N., Fink, B., \& Matts, P.J. (2010). Visible skin condition and perception of human facial appearance. International Journal of Cosmetic Science, 32, 167-184, doi: $10.1111 / \mathrm{j} .1468-2494.2009 .00535 . x$

Saxton, T.K., Caryl, P.G., \& Roberts, S.C. (2006). Vocal and facial attractiveness judgments of children, adolescents and adults: The ontogeny of mate choice. Ethology, 112, 1179-1185, doi: 10.1111/j.1439-0310.2006.01278.x 
Saxton, T.K., Little, A.C., Rowland, H.M., Gao, T., \& Roberts, S.C. (2009). Trade-offs between markers of absolute and relative quality in human facial preferences. Behavioral Ecology, 20(5),1133-1137, doi: 10.1093/beheco/arp107

Scheib, J.E., Gangestad, S.W., \& Thornhill, R. (1999). Facial attractiveness, symmetry, and cues of good genes. Proceedings of the Royal Society B: Biological Sciences, 266, 1913-1917.

Schmitt, D.P., \& Buss, D.M. (1996). Strategic self-promotion and competitor derogation: Sex and context effects on the perceived effectiveness of mat attraction tactics. Journal of Personality and Social Psychology, 70, 1185-1204.

Schmitt, D.P., Couden, A.C., \& Baker, M. (2001). The effects of sex and temporal context on feelings of romantic desire: An experimental evaluation of sexual strategies theory. Personality and Social Psychology Bulletin, 27(7), 833-847, doi: $10.1177 / 0146167201277006$

Schmitt, D.P., \& 118 members of the International Sexuality Description Project. (2003). Universal sex differences in the desire for sexual variety. Tests from 52 nations, 6 continents, and 13 islands. Journal of Personality and Social Psychology, 85, 85104.

Schopenhauer, A. (1970/2004). Essays and Aphorisms (R.J. Hollingdale, Trans.). New York: Penguin Books.

Sefcek, J.A., Brumbach, B.H., Vasquez, G., \& Miller, G.A. (2006). The evolutionary psychology of human mate choice: How ecology, genes, fertility, and fashion influence mating behavior. Journal of Psychology and Human Sexuality, 18, $125-$ 182. 
Sell, A., Cosmides, L., Tooby, J., Sznycer, D., von Rueden, C., \& Gurven, M. (2009). Human adaptations for the visual assessment of strength and fighting ability from the body and face. Proceedings of the Royal Society B: Biological Sciences, 276(1656), 575-584, doi: 10.1098/rspb.2008.1177

Shackelford, T.K., \& Larsen, R.J. (1999). Facial attractiveness and physical health. Evolution and Human Behavior, 20,71-76.

Shackelford, T.K., Schmitt, D.P., \& Buss, D.M. (2005). Universal dimensions of human mate preferences. Personality and Individual Differences, 39, 447-458.

Shuster, S.M. (2009). Sexual selection and mating systems. Proceedings of the National Academy of Sciences of the United States of America, 106, 10009-10016, doi: 10.1073/pnas.0901132106

Simpson, J.A., \& Gangestad, S.W. (2001). Evolution and relationships: A call for integration. Personal Relationships, 8(4), 341-355, doi: 10.1111/j.14756811.2001.tb00044.x

Singh, D. (1993). Adaptive significance of female physical attractiveness: Role of waistto-hip ratio. Journal of Personality and Social Psychology, 65, 293-307.

Singh, D., \& Randall, P.K. (2007). Beauty is in the eye of the plastic surgeon: Waist-hip ratio (WHR) and women's attractiveness. Personality and Individual Differences, 43(2), 329-340, doi: 10.1016/j.paid.2006.12.003

Singh, D., \& Young, R.K. (1995). Body weight, wasit-to-hip ratio, breasts, and hips: Role in judgments of female attractiveness and desirability for relationships. Ethology and Sociobiology, 16(6), 483-507. 
Streeter, S.A., \& McBurney, D.H. (2003). Waist-hip ratio and attractiveness: New evidence and a critique of "a critical test". Evolution and Human Behavior, 24(2), 88-98.

Stroebe, W., Insko, C., Thompson, V., \& Layton, B. (1971). Effects of physical attractiveness, attitude similarity, and sex on various aspects of interpersonal attraction. Journal of Personality and Social Psychology, 18(1), 79-91.

Sugiyama, L.S. (2004). Is beauty in the context-sensitive adaptations of the beholder?: Shiwiar use of waist-to-hip ratio in assessments of female mate value. Evolution and Human Behavior, 25, 51-62.

Sugiyama, L.S. (2005). Physical attractiveness in adaptationist perspective. In D.M. Buss (Ed.), The handbook of evolutionary Psychology (pp.292-343). New Jersey: Wiley.

Swami, V., \& Tovée, M.J. (2005). Female physical attractiveness Britain and Malaysia: A cross-cultural study. Body Image, 2(2), 115-128, doi: 10.1016/j.bodyim.2005.02.002

Tesser, A. (1993). The importance of heritability in psychological research: the case of attitudes. Psychological Review, 100(1), 129-142.

Thornhill, R., \& Gangestad, S.W. (1993). Human facial beauty: Averageness, symmetry, and parasite resistance. Human Nature, 4(3), 237-269, doi: 10.1007/bf02692201

Thornhill, R., \& Gangestad, S.W. (1996). The evolution of human sexuality. Trends in Ecology and Evolution, 11(2), 98-102.

Thornhill, R., \& Gangestad, S.W. (1999). Facial attractiveness. Trends in Cognitive Sciences, 41(2), 147-155. 
Thornhill, R., \& Gangestad, S.W. (2006). Facial sexual dimorphism, developmental stability, and susceptibility to disease in men and women. Evolution and Human Behavior, 27, 131-144, doi: 10.1016/j.evolhumbehav.2005.06.001

Thornhill, R., \& Grammer, K. (1999). The body and face of woman: One ornament that signals quality? Evolution and Human Behavior, 20, 105-120.

Thornhill, R., Gangestad, S.W., Miller, R., Scheyd, G., McCollough, J.K., \& Franklin, M. (2003). Major histocompatibility complex genes, symmetry, and body scent attractiveness in men and women. Behavioral Ecology, 14(5), 668-678, doi: 10.1093/beheco/arg043

Todd, P.M., Penke, L., Fasolo, B., \& Lenton, A.P. (2007). Different cognitive processes underlie human mate choices and mate preferences. Proceedings of the National Academy of Sciences of the United States of America, 104(38), 15011-15016, doi: 10.1073/pnas.0705290104

Tooke, W., \& Camire, L. (1991). Patterns of deception in intersexual and intrasexual mating strategies. Ethology and Sociobiology, 12(5), 345-364, doi: 10.1016/01623095(91)90030

Trivers, R.L. (1972). Parental investment and sexual selection. In B. Campbell (Ed.), Sexual selection and the descent of man 1871-1971 (pp. 136-179). Chicago: Aldine.

Van Doorn, G.S., \& Weissing, F.J. (2004). The evolution of female preferences for multiple indicators of quality. The American Naturalist, 164, 173-186, as retrieved from http://www.jstor.org/stable/3473437 
Waynforth, D. (1998). Fluctuating asymmetry and human male life-history traits in rural Belize. Proceedings of the Royal Society London B: Biological Sciences, 265(1405), 1497-1501, doi: 10.1098/rspb.1998.0463

Wedell, D.H., Parducci, A., \& Geiselman, R.E. (1987). A formal analysis of ratings of physical attractiveness: Successive contrast and simultaneous assimilation. Journal of Experimental Social Psychology, 23(3), p. 230-249.

Wells, J., Dunn, A.K., Sergeant, M.J.T., \& Davies, M.N.O. (2009). Multiple signals in human mate selection: A review and framework for integrating facial and vocal signals. Journal of Evolutionary Psychology, 7, 111-139, doi:

10.1556/JEP.7.2009.2.2

Wright, S. (1931). Evolution in Mendelian populations. Genetics, 16, 97-159.

Zahavi, A. (1977). The cost of honesty (further remarks on the handicap principle). Journal of Theoretical Biology, 67(3), 603-605.

Zebrowitz, L.A., \& Rhodes, G. (2004). Sensitivity to "bad genes" and the anomalous face overgeneralization effect: Cue validity, cue utilization, and accuracy in judging intelligence and health. Journal of Nonverbal Behavior, 28(3), 167-185, doi: 10.1023/B:JONB.0000039648.30935.1b 